\title{
ILCEA
}

Revue de l'Institut des langues et cultures

d'Europe, Amérique, Afrique, Asie et Australie

$15 \mid 2012$

Les mots de la crise

\section{Réception et traitements de termes spécialisés anglais liés à la crise financière dans la presse espagnole : 2007-2009}

Reception and treatment of specialised English terms related to the financial crisis in the Spanish press: 2007-2009

\section{Setty Alaoui Moretti}

\section{OpenEdition}

\section{Journals}

Édition électronique

URL : http://journals.openedition.org/ilcea/1184

DOI : 10.4000/ilcea. 1184

ISSN : 2101-0609

\section{Éditeur}

UGA Éditions/Université Grenoble Alpes

\section{Édition imprimée}

ISBN : 978-2-84310-220-2

ISSN : 1639-6073

\section{Référence électronique}

Setty Alaoui Moretti, «Réception et traitements de termes spécialisés anglais liés à la crise financière dans la presse espagnole : 2007-2009 », ILCEA [En ligne], 15 | 2012, mis en ligne le 18 décembre 2013, consulté le 23 avril 2019. URL : http://journals.openedition.org/ilcea/1184 ; DOI : 10.4000/ilcea. 1184

Ce document a été généré automatiquement le 23 avril 2019

(c) ILCEA 


\title{
Réception et traitements de termes spécialisés anglais liés à la crise financière dans la presse espagnole : 2007-2009
}

\author{
Reception and treatment of specialised English terms related to the financial \\ crisis in the Spanish press: 2007-2009
}

Setty Alaoui Moretti

\section{NOTE DE L'AUTEUR}

L'auteur exprime ici sa gratitude envers les deux relecteurs anonymes de ce travail et tient à les remercier pour leurs observations et suggestions très constructives.

1 Dans le cadre de notre activité de recherche multilingue au sein du GREMUTS, et dans une perspective résolument interculturelle, nous nous sommes proposés de réfléchir sur les différentes «mises en mots de la crise des subprimes » - et de leurs relations - ainsi que sur la réalité complexe et variée de la circulation des savoirs dans le monde financier et économique des aires linguistiques représentées au sein de notre laboratoire. La langue peut-elle être un enjeu et un facteur économique? Quelle place occupe-t-elle dans l'évaluation et la modélisation des processus économiques au sens large? (Voir éditorial.)

2 La première difficulté à laquelle nous nous sommes confrontés fut l'ampleur du corpus de presse et l'éclectisme des genres discursifs inhérent à l'hétérogénéité des articles tant au niveau sémiotique qu'aux niveaux textuel et énonciatif. Après avoir déterminé le moment discursif qui donna lieu à la plus importante production médiatique du fait de l'apparition de termes spécifiques à la crise des subprimes (juillet 2007-décembre 2009), notre analyse commune s'est structurée autour de trois axes : 
les aspects lexicaux (terminologie, métaphorisation, phraséologie, problèmes traductologiques);

les aspects textuels (traitement des questions économiques dans les médias, formes de l'argumentation dans les textes économiques, structuration narrative de l'information économique) ;

les aspects pragmatiques et discursifs (discours spécifique de la crise, comparaison du traitement d'un même phénomène économico-financier dans différentes aires linguistiques).

\section{Le corpus}

Le corpus de la présente étude, la presse espagnole générale et spécialisée, nationale et régionale ${ }^{1}$, a été constitué avec le moteur de recherche Factiva selon les paramètres suivants :

période analysée : juillet 2007-décembre 2009 ;

domaine : information économique ;

région : Espagne ;

langue : espagnol ;

presse générale et spécialisée, nationale et régionale, avec principalement au niveau

national $^{2}$ : Gaceta de los Negocios, Expansión, Actualidad Económica, Actualidad Financiera, El Economista, Diario Financiero, Dinero, El País, El Mundo, Cinco Días, ABC, La Razón, La Vanguardia.

définition d'une liste de termes spécifiques à la crise financière - dite des subprimes - par pic d'usage : bubble, subprime, securitization, bad bank, delinquency ou default, toxic asset ou TARP, SWAP ou CDS, hedge fund, recession, recovery.

Notre objectif s'est centré non seulement sur l'étude des discours des journalistes sur l'économie mais également sur les discours de l'activité financière et économique ellemême : du fait de la différence de culture professionnelle, les spécialistes et les nonspécialistes emploient une terminologie et un style différents pour désigner une même réalité. Il est vrai que la «langue économique » en tant que telle n'existe pas, mais il existe des façons de parler et d'écrire dans des situations professionnelles qui relèvent du domaine économique, comme il existe des façons de parler et d'écrire à propos de faits économiques. Ce sont donc les activités langagières du monde de l'économie et de la finance qui, d'une façon générale, ont inspiré cette recherche sur le thème de «la réception et du traitement des mots de la crise financière ». Nous nous proposons d'aborder cette analyse à partir de la double approche de la réalité objective (apparition du terme, pic d'emploi, disparition) et du phénomène de psychologie collective. Car si les mots révèlent ce que l'on valorise et ce que l'on espère, ils dévoilent aussi ce que l'on rejette et ce que l'on occulte : les craintes, les doutes, le déni.

\section{Quelques données macroéconomiques et la bulle immobilière en Espagne}

Dans la crise financière des subprimes qui a éclaté en Europe en août 2007, l'Espagne apparait comme un cas particulier au sein de l'Union européenne du fait de la conjonction des effets de la crise mondiale et de facteurs spécifiquement internes tels la 
surabondance de liquidité, la surproduction de biens immobiliers et l'attitude permissive des autorités monétaires. Depuis la période franquiste, les deux moteurs principaux de l'économie sont le tourisme et le secteur immobilier. Une panoplie d'avantages fiscaux conséquents $^{3}$ a fabriqué des générations de propriétaires et cette politique pése encore sur le secteur immobilier qui représente $21 \%$ du PIB.

Il est vrai que durant les quinze dernières années, l'Espagne a réalisé des performances remarquables notamment en matière de croissance et d'emploi. Entre 1996 et 2006, le taux de croissance moyen a été de $4 \%$ (contre 2,8 \% dans la zone euro), l'écart du PIB par habitant par rapport à la moyenne de l'Union européenne a été de $12 \%$ en 2005 (contre 20 \% en 1995) et le taux de chômage a fortement baissé : 8,3 \% en 2006 (contre $16 \%$ en 1999) comme en attestent les diagrammes suivants :

Figure 1. - Taux de croissance du PIB réel (source : Eurostat).

\section{Tasas de crecimiento PIB real}

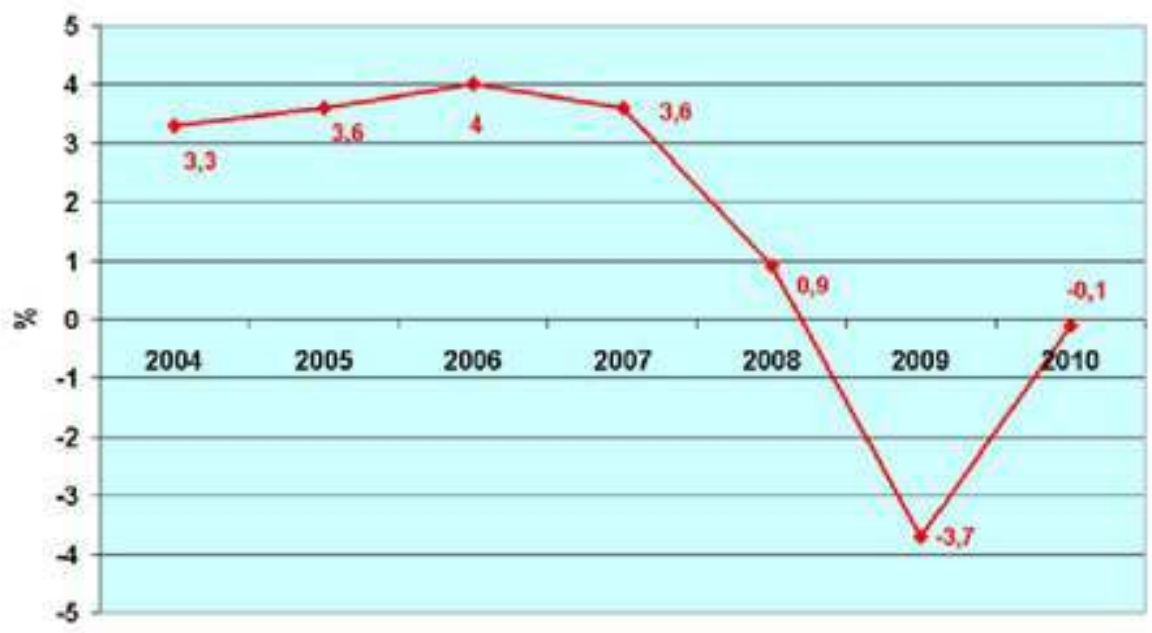

Figure 2. - Taux de chômage (source : Eurostat).

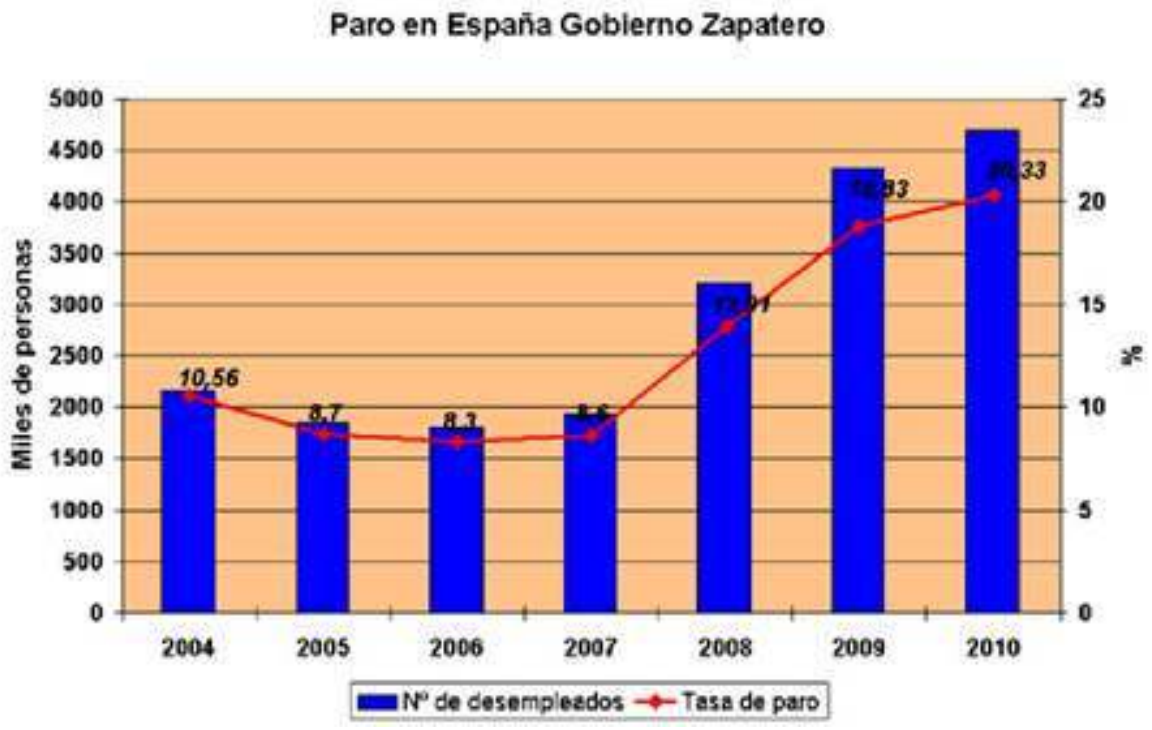


7 Cette forte croissance a été stimulée par la combinaison des conditions monétaires favorables à l'investissement, par une gestion budgétaire prudente qui a permis aux comptes publics de dégager des excédents à partir de 2005 (1,1\% en 2005 et $2,4 \%$ en 2007), par des réformes structurelles adéquates et par la contribution positive d'une forte immigration dont le chiffre a augmenté de $529 \%$ en dix ans. En 2010, l'Espagne compte 4744169 résidents étrangers (11,5\% de la population) : des immigrants maghrébins, latino-américains et d'Europe de l'Est mais aussi de riches étrangers investissant dans l'immobilier en résidences secondaires ${ }^{4}$. Par ailleurs, du fait d'une fiscalité défavorable pour les locataires et propriétaires bailleurs, la marginalité du parc locatif espagnol ${ }^{5}$ est saisissante : il ne représente que $11 \%$ de l'ensemble du parc (contre $70 \%$ en Suisse par exemple) et le logement social en accession à la propriété ne représente que $1 \%$ ! La frilosité des propriétaires se justifie également par la longueur des procédures d'expulsions en cas de loyers impayés. En 2009, le gouvernement s'est engagé sur une procédure accélérée d'expulsion lors d'un avant projet de réforme de la loi sur les baux immobiliers urbains.

Il n'est donc pas surprenant que l'immobilier ait connu une croissance exponentielle. En plein " miracle économique ", les constructions de résidences fleurissent même en plein désert, le littoral est « bétonné » à tout va. Il est clair que la mégalomanie de certains promoteurs et la corruption d'élus locaux, gérants de l'offre foncière, ont amplifié la surproduction immobilière. Au cours des années précédant la crise, on construisait une moyenne de 800000 logements par an, soit autant que la France, l'Allemagne et la Grande-Bretagne réunies ${ }^{6}$.

9 L'accession à la propriété, un désir très ancré dans la mentalité espagnole, a toujours été fortement encouragée par les gouvernements, notamment par des mesures fiscales qui permettaient de déduire des revenus environ $15 \%$ du montant des intérêts d'emprunt immobilier.

10 Par ailleurs, durant ces dernières années, la structure familiale espagnole s'est légèrement modifiée: la structure monoparentale s'est développée du fait de l'augmentation des divorces, les jeunes couples avancent l'âge de leurs premières cohabitations, et les jeunes adultes (25-35 ans) s'installent dans leurs propres logements ${ }^{7}$. Mais si cette évolution a relancé la demande en logement, les promoteurs en ont construit beaucoup plus que nécessaire : 5,5 millions de logements neufs pour 3,5 millions de nouveaux ménages constitués ${ }^{8}$ entre 1997 et 2006. Investir dans la pierre étant considéré comme un investissement sur l'avenir, nombreux sont ceux qui ont acquis un logement, soit en tant que logement «tirelire» (pisos-hucha) pour assurer l'avenir de leurs enfants, soit dans l'espoir de réaliser une plus-value à la revente. C'est pourquoi l'Espagne est le pays où le taux de propriétaires est le plus élevé d'Europe : $82 \%$ en 2008 alors que la moyenne dans les pays de l'Union européenne est de 57,4\%\%.

11 Entre 1995 et 2007, les prix de l'immobilier en Espagne ont augmenté de 91 \% générant une augmentation forte et constante des plus values: au cours des vingt dernières années, le prix moyen d'un logement neuf a été multiplié par sept, selon la Sociedad de Tasación, cabinet spécialisé dans les estimations d'actifs immobiliers ${ }^{10}$. La forte demande dans ce secteur a été motivée d'une part, par l'effondrement des taux d'intérêts hypothécaires (de 2,7 à $4 \%$ actuellement contre $16 \%$ au début des années 1990) qui a accompagné l'entrée de l'Espagne dans la zone euro, et d'autre part, par une forte création d'emplois (+ 1 million). 
Figure 3. - Prix de l'immobilier et taux d'inflation sur la période 1984-2011, en euros $/ \mathrm{m}^{2}$ (source : Institut Eurostat).

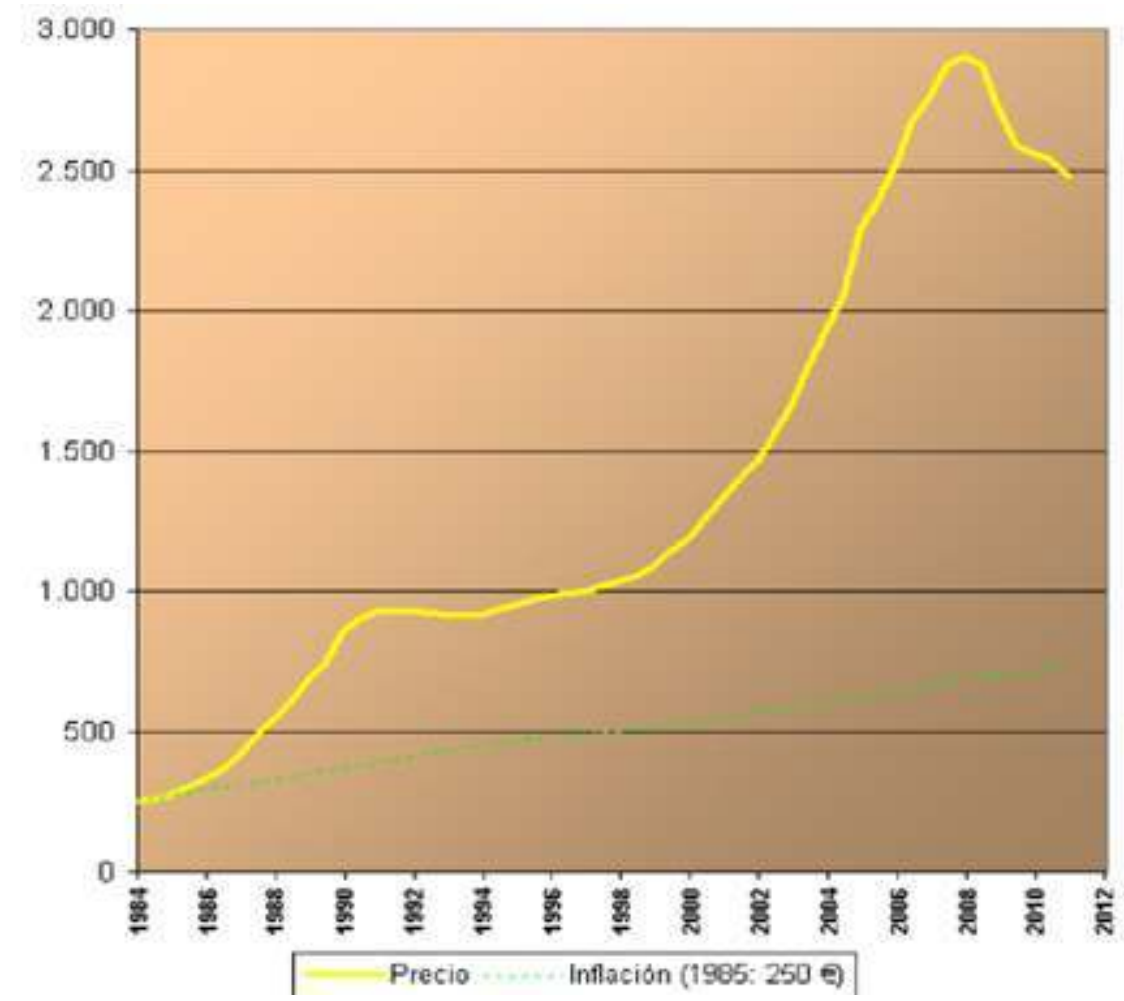

12 Les banques et les Caisses d'épargne se sont précipitées pour consentir de plus en plus de prêts aux particuliers et aux promoteurs immobiliers, à hauteur d'environ $60 \%$ de leurs actifs (1 020 milliards d'euros) ce qui suppose une forte concentration des risques ${ }^{11}$. Les prêts aux particuliers ont été accordés indépendamment de l'âge et de la situation (retraités, primo-accédants, smicards), sur des durées de 30 ou 40 ans, voire 50 ans, à des taux faibles car variables, les Espagnols étant réfractaires aux taux fixes ${ }^{12}$ pour des raisons difficilement explicables par les experts et les banquiers.

Tant que la croissance de l'immobilier était au rendez-vous, ce système fonctionnait à la satisfaction de tous mais, forts des facilités de crédits offertes, les promoteurs ont ouvert des chantiers toujours plus nombreux jusqu'à se heurter à la limite naturelle de la loi de l'offre et de la demande. On dit souvent que lorsque l'économie européenne va bien, l'économie espagnole va très bien et que lorsque l'économie européenne va mal, l'économie espagnole va très mal : de l'autre côté des Pyrénées, tout est amplifié.

$\mathrm{Au}$ cours du deuxième semestre 2006, lorsque les constructions réalisées peinent à trouver preneur, la machine commence à s'enrayer et durant le premier semestre 2007, la vente de constructions neuves s'effondre. Lorsque la bulle explose, c'est la grande braderie : il n'est pas rare de voir un promoteur liquider deux appartements pour le prix d'un, un autre promoteur offrir une voiture ou une moto avec la maison, et les villes fantômes - véritables no man's land sortis de nulle part - se multiplient dans toute l'Espagne.

À la fin de l'année 2008, près d'un tiers des logements (soit 1200 000) construits durant la période 2001-2007 sont vides. Les villes fantômes symbolisent à elles seules la crise de l'immobilier en Espagne: au sud de Madrid, la ville nouvelle de Seseña fut conçue pour 
accueillir 40000 habitants mais n'en compte à ce jour que 3000 , perdus dans les rues désertes et au milieu de dizaines de bâtiments inachevés; au nord de Madrid, Monte Carmelo totalise $1 \mathrm{M}$ de logements invendus et Bienvenidos à Valdeluz, initialement prévue pour 34000 habitants, n'en compte que 384 .

Dans l'incapacité d'honorer leurs échéances, un certain nombre de promoteurs est acculé à la faillite dès la fin de l'année 2007. C'est le cas, en janvier 2008, du grand promoteur Colonial, figure de l'âge d'or de l'immobilier espagnol. Les banques qui ont prêté jusqu'à $60 \%$ de leurs encours (910 milliards environ) à ce secteur, se trouvent donc fortement fragilisées. Les particuliers qui avaient investi avec la certitude de réaliser de fortes plusvalues voient leurs espoirs s'évaporer face au déséquilibre total de l'offre par rapport à la demande. En outre, on constate une hausse conséquente des taux variables et les emprunteurs particuliers sont alors dans l'incapacité de rembourser leurs échéances. Nombreux sont ceux qui mettent en vente leurs biens sur le marché immobilier mais très peu réussissent à trouver acquéreur face au volume surdimensionné de l'offre de logements neufs généré par la spéculation et l'activité fébrile des promoteurs ${ }^{13}$.

Dans le droit espagnol, en matière de logement, le «tout urbanisable » prévaut. Si les pouvoirs publics souhaitent " protéger » un espace, il leur revient d'en faire la démarche pour motiver la protection, à l'inverse de ce qui se passe en France. La loi du sol parue en 2007 établit le cadre d'une politique sociale de logements aidés; $30 \%$ des nouveaux espaces urbanisés consacrés à un usage résidentiel doivent être dévolus à la construction de logements dits "protégés » (équivalents des logements sociaux en France). Mais ces mesures n'ont pas été forcément respectées, d'où la folie constructrice de certains promoteurs immobiliers pour entreprendre des programmes de construction sur le moindre lopin de terre disponible.

Les économistes sont unanimes pour affirmer que la bulle aurait éclaté en Espagne au plus tard en 2009, indépendamment de la crise américaine qui n'a fait qu'accélérer les choses et que la responsabilité doit être assumée à $100 \%$ par les Espagnols ${ }^{14}$. La position $\mathrm{du}$ Gouvernement est tout autre et les prochaines élections législatives de mars 2008 apparaissent comme la raison première du déni.

\section{Les mots de la crise : traduction et « définitions ${ }^{15}$ »}

Les mutations économiques importent de nouveaux concepts de l'étranger qui doivent ensuite être introduits dans la langue d'accueil. Le travail terminologique sur les notions émergentes incombe à l'intermédiaire, qu'il soit traducteur ou journaliste : pour rendre accessibles à un large public des objets techniques nouveaux ou peu connus, il aura recours à l'emprunt (xenism, calque), à l'explicitation du concept (équivalent, adaptation) ou à la création plus ou moins hasardeuse de néologismes. Dans le domaine de la terminologie, les nouvelles notions donnent parfois lieu à des jeux langagiers comme las hipotecas basura (les hypothèques poubelles, construit sur le modèle de la televisión basura, la télévision poubelle) ou las hipotecas ninja, las familias ninja ou los ninjas (acronyme de No Incomes, No Jobs no Assets ${ }^{16}$ ) pour désigner respectivement les hypothèques à haut risque, les familles très endettées et les personnes peu ou non solvables. Au milieu du raz-de marée de termes financiers anglo-saxons qui inonde les medias, c'est un Espagnol, Leopoldo Abadía, qui est à l'origine de cet acronyme qui va faire fureur. Ces formules deviennent très rapidement des mots-références ou mots-événements qui passent dans le langage commun. 
20 La différence la plus marquée entre le discours d'une spécialité et le discours de la vulgarisation d'une spécialité est l'omniprésence de définitions ou de pseudo-définitions. En effet, le lecteur est souvent confronté à des approximations, des généralisations ou des simplifications qui lui donnent l'illusion d'une explication souvent introduite par des articulations métalinguistiques telles que « la llamada, lo que podríamos denominar, lo que significa, definida como, etc. ${ }^{17}$ ». La fréquence d'emploi des guillemets renforce la confusion et le lecteur ne sait plus si ceux-ci signalent un terme authentique ou s'ils proposent la traduction en langage simple d'un terme savant. Alors que le discours journalistique explicatif se présente habituellement sous la modalité de l'affirmation, les nombreuses marques de modalisation du discours sur la crise financière - qui potentialise l'effet d'incertitude et de doute - témoignent de la difficulté des journalistes à expliquer les mécanismes financiers complexes et douteux d'une crise qu'ils n'ont pas été à même d'anticiper.

21 Car si la crise des subprimes commence à se manifester aux États-Unis dès le deuxième trimestre 2006, avec le krach des prêts immobiliers hypothécaires à risque, ce n'est qu'en février 2007 que le terme apparaît dans la presse espagnole ${ }^{18}$ quand le Wall Street Journal met en garde contre les subprimes et que l'on apprend que la banque HSB a passé d'importantes provisions.

\section{Subprime}

Le terme subprime a connu plusieurs traductions en espagnol. Durant le premier semestre 2007, et toujours en référence à la crise aux États-Unis, des périphrases définitionnelles accompagnent le terme : préstamos otorgados a personas de algo riesgo crediticio, hipotecas de alto riesgo concedidas a personas con poca solvencia, créditos de peor calidad y mayor riesgo ${ }^{19}$ (22 occurrences). À partir de l'été 2007, les subprimes font la une des journaux et les références portent sur le marché, le secteur ou le segment des subprimes : sector hipotecario subprime, segmento subprime, mercado subprime ${ }^{20}$. Le risque de propagation à l'Europe se concrétise et apparaissent enfin des traductions graduelles plus précises portant sur l'hypothèque en Espagne: préstamos subprime, hipotecas subprime, hipotecas de alto riesgo subprime (557 occurrences, pic en 2007), hipotecas basura (604 occurrences, pic en 2008) et hipotecas ninjas. 
Figure 4. - Subprime, 662 occurrences en 2007 (source : Factiva).

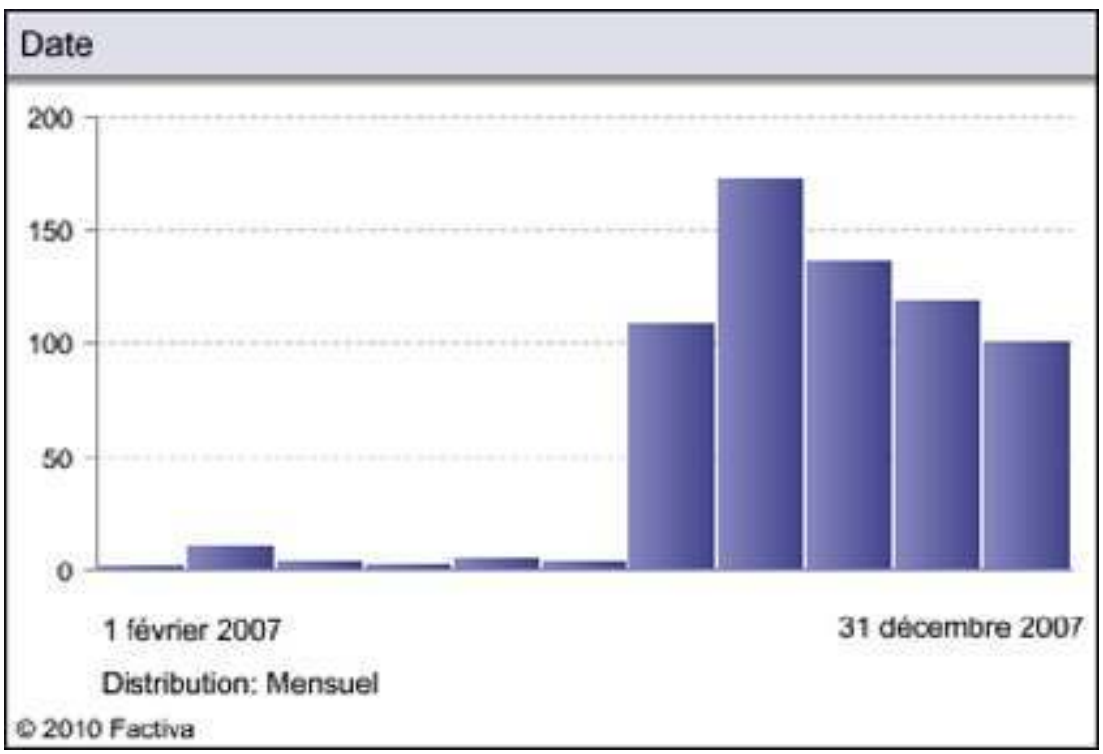

Au cours du deuxième semestre 2007, on ne compte pas moins de 640 occurrences du terme subprime. En effet, entre la fin du mois de juillet et septembre 2007, les nouvelles alarmantes se succèdent avec l'effondrement de la valeur de deux fonds d'investissement de la banque américaine Bear Stearns, la première chute des marchés boursiers, l'annonce de graves difficultés pour certaines grandes banques européennes (IKB Deutsche Industriebank, BNP Paribas, UBS, Crédit Suisse, etc.) et l'intervention massive des banques centrales (BCE, FED) suivie de la baisse des taux directeurs.

En octobre et novembre 2007, le nombre d'occurrences fléchit car si la crise progresse, les nouvelles sont moins sensationnelles. Le premier choc s'estompe. Mais dès la fin du mois de décembre, une nouvelle vague d'informations alarmantes déferle: l'UBS, première banque suisse, annonce des pertes capitalistiques de 10 milliards de dollars. Cinq banques centrales (BCE, FED, Bank of England, Banque du Canada et Banque nationale suisse) lancent une action concertée pour lutter contre la crise de liquidités et les États-Unis entrent en récession.

En janvier 2008, on enregistre une remontée brutale des occurrences du terme subprime (150 occurrences) dans la presse espagnole. Au cours de l'année 2008, elles se maintiendront à un niveau élevé : 962 occurrences dont près des deux tiers au cours du premier semestre (611 occurrences). 
Figure 5. - Subprime, 962 occurrences en 2008 (source : Factiva).

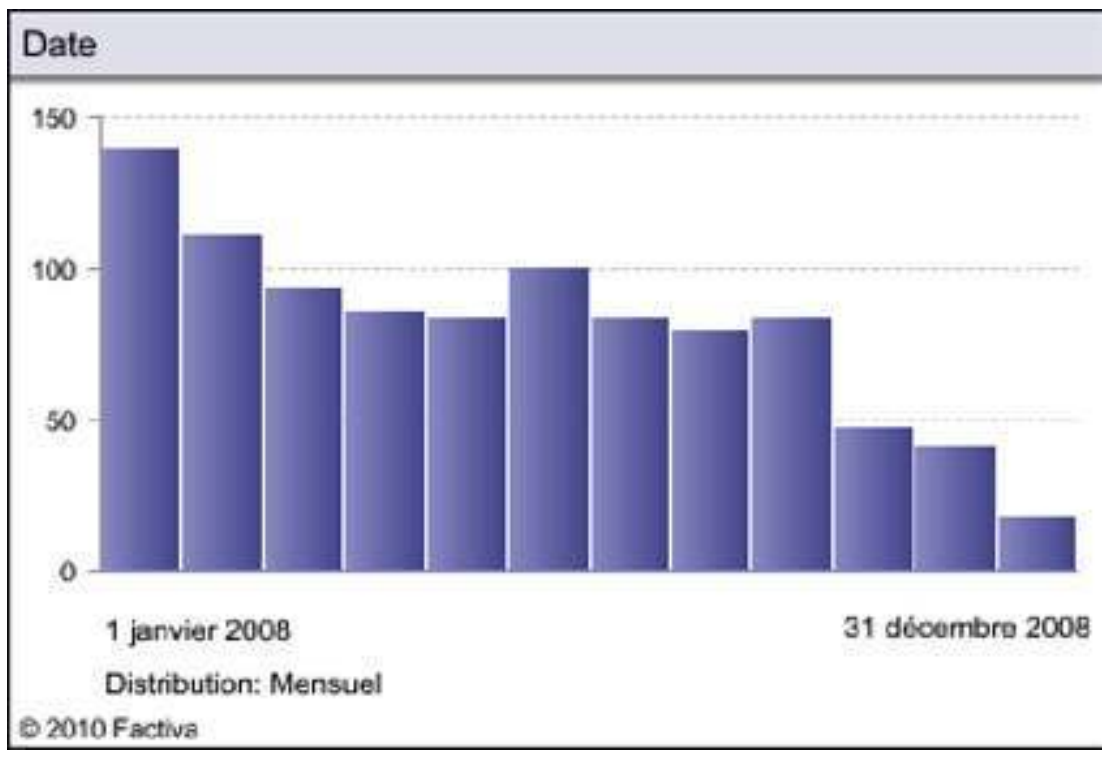

Les nouvelles cessent d'être alarmantes pour devenir angoissantes du fait de la forte baisse des places boursières mondiales ( 21 janvier 2008) et de la hausse du taux de chômage annoncée par le Bureau International du Travail (estimation: 5 millions de chômeurs). De plus, Jean-Claude Juncker, président d'Eurogroupe ${ }^{21}$, avance un chiffre de 400 milliards de dollars pour pertes liées à la crise du crédit hypothécaire américain. La liste des banques et établissements financiers en extrême difficulté s'allonge (Northern Rock, Bear Stearns, J.P. Morgan Chase, Alliance \& Leicester rachetée par Banco de Santander, Dresdner Bank, Fanny Mae, Freddie Mac, Fortis, la compagnie d'assurance AIG et l'assureur mondial ING Internationale Nederlanden Groep). L'Irlande, le Royaume Uni, l'Italie, l'Espagne (qui a supporté un temps en Europe la moitié des licenciements dus à la crise), puis l'Allemagne et la France entrent en récession. À cela s'ajoute la faillite de la banque Lehman Brothers qui expose dangereusement l'ensemble du système bancaire américain suivie de la semaine noire (du 6 au 10 octobre 2008) pour les principales bourses qui s'effondrent.

Le terme hipotecas basura (249 occurrences) va se généraliser du fait des différents plans d'action mis en œuvre par les gouvernements européens et nord-américain, suivi de près par l'emploi de hipotecas de alto riesgo (151 occurrences). 
Figure 6. - Hipotecas basura, 249 occurrences (source : Factiva).

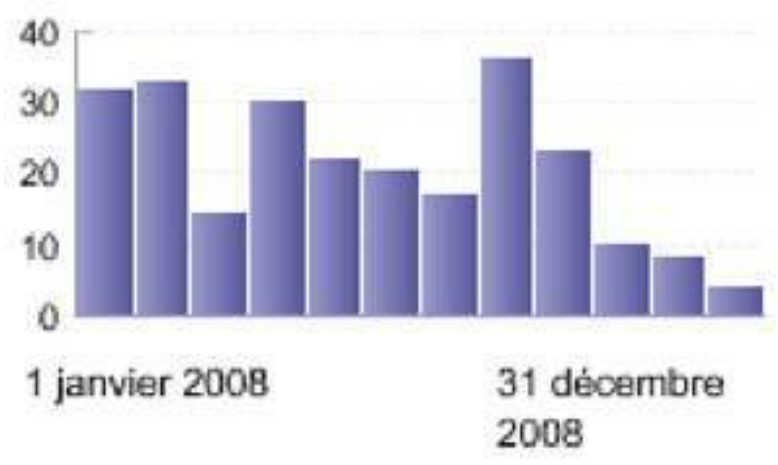

\section{Distribution: Mensuel}

Figure 7. - Hipotecas de alto riesgo, 151 occurrences (source : Factiva).

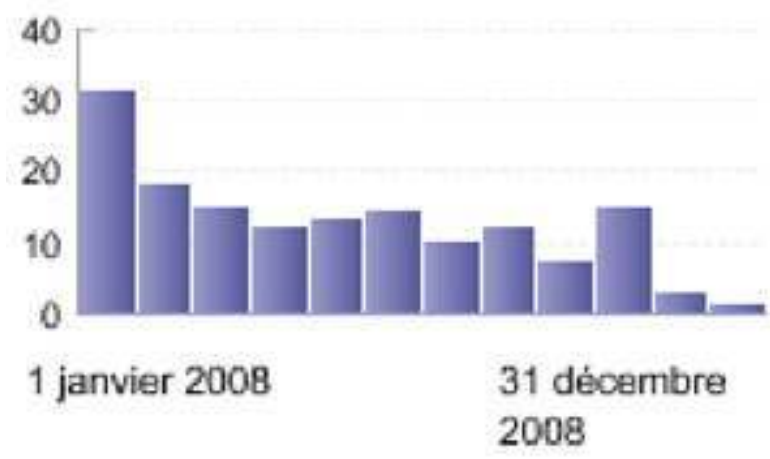

\section{Distribution: Mensuel}

28 Si le début de l'année 2009 voit l'économie espagnole - la quatrième de la zone euro s'enfoncer dans la récession, les mesures prises par les différents gouvernements des grandes puissances économiques commencent à porter leurs fruits et le risque du chaos financier mondial s'éloigne pour un temps: les nouvelles préoccupations se nomment Grèce et déficit public. Les occurrences de subprime se raréfient : en 2009, nous en avons relevé 172 dont 101 durant le premier semestre et 71 au deuxième semestre. 
Figure 8. - Subprime, 172 occurrences en 2009 (source : Factiva).

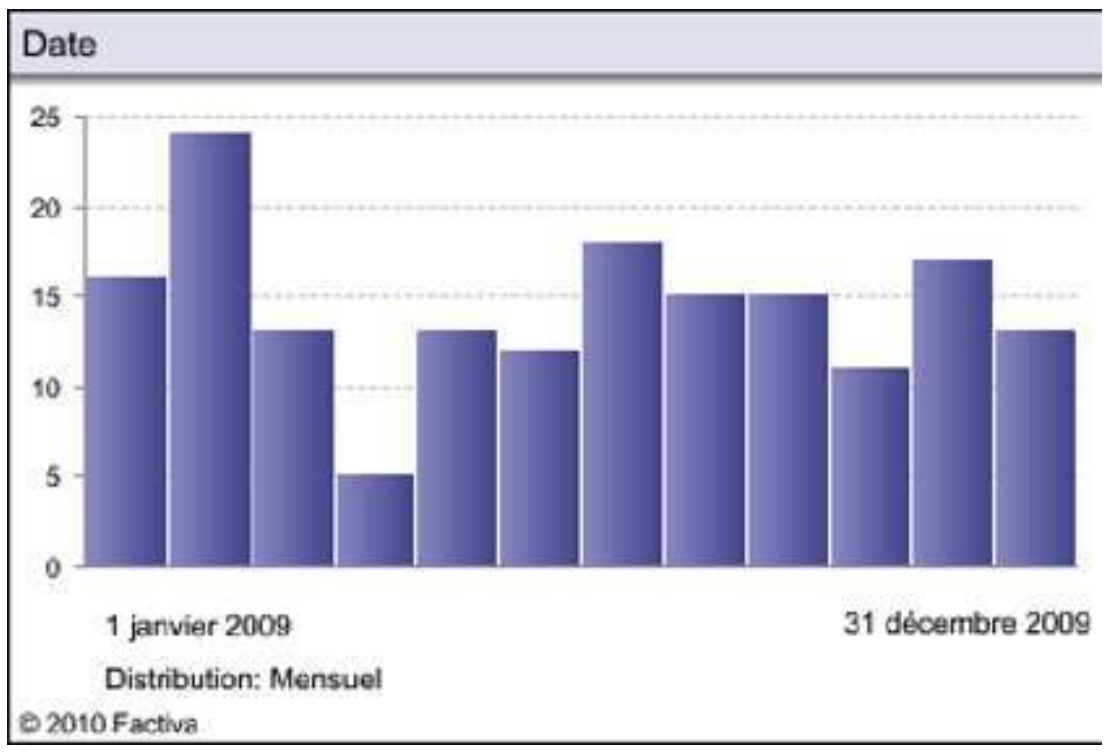

Figure 9. - Occurrences qualifiant le terme subprime et ses traductions ou équivalents (Total des occurrences : 3593 )

\begin{tabular}{|l|l|l|l|l|}
\hline & 2006 & 2007 & 2008 & 2009 \\
\hline Sector hipotecario subprime & 0 & 8 & 0 & 0 \\
\hline Negocio subprime & 0 & 8 & 0 & 0 \\
\hline Préstamos subprime & 0 & 9 & 0 & 3 \\
\hline Mercado hipotecario subprime & 0 & 10 & 2 & 0 \\
\hline Segmento subprime & 0 & 13 & 2 & 0 \\
\hline Mercado subprime & 0 & 13 & 7 & 1 \\
\hline Subprime & 0 & 662 & 962 & 172 \\
\hline Hipotecas subprime & 0 & 216 & 290 & 67 \\
\hline Hipotecas de alto riesgo & 1 & 384 & 154 & 18 \\
\hline Hipotecas basura & 0 & 248 & 249 & 81 \\
\hline Total & 1 & 1579 & 1671 & 342 \\
\hline
\end{tabular}

De 2007 à 2008, le gouvernement, les banquiers et de nombreux économistes affirment haut et fort qu'il n'existe pas en Espagne de marché subprime (hipotecas de alto riesgo) comme aux États-Unis et ce, en dépit des nombreuses publicités dans les médias : credifacil , crédito vida libre, crediya, credial, crediútil, dineroya, crediagil, dinero express ${ }^{22}$. Les titres de 
presse relaient le discours officiel, les banques espagnoles sont fortes, le marché est transparent et la solvabilité est sans faille :

"Vegara (secretario de Estado de Economía) afirma que en España no existe un mercado de hipotecas de alto riesgo como en Estados Unidos" [Vergara, secrétaire d'État au ministère de l'Économie, affirme que le marché des hypothèques à haut risque n'existe pas en Espagne, contrairement aux États-Unis], El Economista, 12 juillet 2007.

«España, a salvo de 'hipotecas basura'» [L'Espagne à l'abri des hypothèques poubelles], La Verdad, 11 août 2007.

« Miedo al miedo » [Peur de la peur], El Mundo, 13 juillet 2007.

"La subida de los tipos de interés no echarán por tierra las vacaciones de este verano " [La hausse des taux d'intérêt n'empêchera pas les départs en vacances cet été], $L a$ Vanguardia, 29 juillet 2007.

«El fantasma de la crisis del crédito » [Le fantôme de la crise du crédit], Cinco Días, 10 août 2007.

«El Ministerio de Economía dice que no se conceden en España las hipotecas que causan el temor en América » [Le ministère de l'Économie affirme que les hypothèques qui provoquent tant de crainte aux États-Unis ne se pratiquent pas en Espagne], Cinco Días, 11 août 2007.

"El efecto de la crisis 'subprime' será casi nulo en España, según Solbes » [Selon Solbes, l'effet de la crise subprime sera pratiquement nul en Espagne], Expansión, 9 octobre 2007.

" Fuerte optimismo pese a la crisis de las 'subprime' » [Grand optimisme malgré la crise des subprimes], Gaceta de los Negocios, 12 octobre 2007.

"La calidad de las hipotecas españolas está fuera de duda » [La qualité des hypothèques espagnoles est inattaquable], La Voz de Galicia, 26 octobre $2007^{23}$.

Néanmoins, durant l'été 2007, $55 \%$ des Espagnols ne partent pas en vacances et $35 \%$ d'entre eux doivent consentir des sacrifices inédits sur les sorties au restaurant, au cinéma, etc., renonçant ainsi à de nombreuses habitudes. L'endettement des ménages atteint $80 \%$ du PIB. L'explication officielle de la perte de clientèle des restaurants est immédiate : la crise touchant durement les voisins européens, il est normal qu'il y ait moins de touristes (ce qui est par ailleurs avéré). Les élections législatives de mars 2008 approchent...

31 À l'automne 2007, on s'accorde toujours à dire que la crise hypothécaire ne touche pas l'Espagne mais que celle-ci doit se protéger des éclats car lorsque les États-Unis éternuent, le monde entier s'enrhume. Officiellement, on reconnaît qu'il y a un manque de liquidité dans le secteur bancaire et que les taux de l'Euribor ont augmenté; ceci provoquant cela, il n'y a pas lieu de s'inquiéter.

En décembre 2007, la Fondation des Caisses d'Epargne (FUNCAS) déclare que $40 \%$ des familles ont un crédit et que seuls $15 \%$ sont en difficulté ${ }^{24}$. Ils représenteraient donc ce que l'on pourrait appeler le segment subprime espagnol (marché des hypothèques à haut risque, mercado hipotecario de alto riesgo).

$\mathrm{Au}$ début de l'année 2008, les journaux commencent à évoquer l'imminence de la tempête: "grandes nubarrones, el miedo, el temor, el vendaval, la tormenta, el agotamiento » (de gros nuages, la peur, la crainte, la tempête, l'ouragan, l'épuisement). La perte de confiance dans le système financier génère la crainte et la peur. Une fois les élections du 9 mars 2008 passées, le président Zapatero entame son deuxième mandat et déclare fermement que la crise ne sera qu'une « parenthèse transitoire » et que l'Espagne «retrouvera les niveaux du précédent mandat» avant la fin 2009, avec un retour à la croissance estimé à $3 \%$. Durant cette "parenthèse ", José Luis Zapatero entend puiser 
dans les "marges budgétaires" accumulées lors des dernières années pour soutenir l'activité économique par un programme de relance. Il est vrai que, servie par une croissance vigoureuse, l'Espagne a dégagé depuis plusieurs années des comptes publics excédentaires, performance rare en Europe qui mérite d'être saluée.

En juin 2008, le président Zapatero déclare à un pays qui cumule inflation, remontée du chômage, atterrissage brutal du fait de l'éclatement de la bulle immobilière et $1,2 \%$ de croissance en rythme annuel :

« En premier lieu, nous allons réduire d'au moins 30 \% l'offre publique d'emploi pour 2009, tout en préservant certains secteurs essentiels comme la sécurité, la justice, l'inspection du travail. De plus, vendredi prochain, le Conseil des ministres va geler 20 millions d'euros de dépenses prévues dans le budget en cours, et notamment les hausses de salaires de tous les hauts fonctionnaires ${ }^{25}$. »

L'objectif est d'économiser "au moins 250 millions d'euros entre 2008 et 2009 ». Le commissaire européen aux affaires économiques, Joaquin Almunia, assure les banques espagnoles de toute sa confiance car elles sont «très bien préparées " pour réagir face à la crise et il salue le "travail rigoureux" de la banque d'Espagne durant le boom immobilier ${ }^{26}$. (6/05/2008, Onda Cero). Enfin, même si la commission européenne a revu à la baisse les prévisions de la croissance de l'Espagne, pour les années $2008(+2,2 \%)$ et 2009 $(+1,8 \%)$ - initialement prévues à $2,7 \%$ et $2,3 \%$ - le pays conserve des chiffres supérieurs aux prévisions faites pour l'ensemble de la zone euro.

L'été arrive et en 24 heures, le jeudi 24 juillet, trois annonces viennent symboliser l'ampleur de la crise qui touche l'Espagne. Le gouvernement espagnol abaisse une nouvelle fois sa prévision de croissance, une habitude depuis plusieurs semaines. Désormais, Madrid estime que la croissance du produit intérieur brut s'élèvera à 1,6\% pour 2008 ( $1 \%$ en 2009) contre une prévision officielle antérieure de $2,3 \%$. La chute sera donc brutale après un taux de croissance de $3,8 \%$ en 2007. Sous la pression des experts réunis à La Moncloa, Madrid reconnaît l'ampleur du ralentissement ${ }^{27}$. Dans un entretien publié le 3 août dans le quotidien El País, le ministre de l'Économie, Pedro Solbes, reconnaît que « la situation économique est pire que ce que nous prévoyions tous. Nous pensions que cela irait un peu plus lentement mais finalement, c'est allé plus vite ${ }^{28}$ ».

En septembre 2008, pour la première fois depuis la récession non nommée, la Banque d'Espagne et le gouvernement doivent sauver un établissement financier, la Caisse d'Épargne de Castille-la-Manche et, en novembre 2008, le gouvernement Zapatero accorde des facilités aux chômeurs pour le remboursement de leurs appartements, une petite consolation car le pire est à venir.

Le réveil brutal a lieu en 2009. Le gouvernement Zapatero reconnaît enfin qu'il y a bien une crise «même si elle n'est pas bien méchante » et que quelques mois suffiront pour redresser la barre. Il opte pour un changement radical de sa politique économique. Des mesures sont prises afin de valoriser le locatif et le logement "aidé » (équivalent du logement social en France). Une aide est allouée aux promoteurs immobiliers afin qu'ils s'engagent à mettre à bail les logements non vendus. Une mise aux enchères du patrimoine foncier régi par les communes est également prévue afin qu'elles puissent se financer. Enfin, la loi du sol, adoptée en 2007, met fin au « tout urbanisable » des années précédentes qui a permis cette boulimie constructrice. La crise du logement espagnol est définitivement due à un choix politique ancien dont il est difficile de se défaire dès lors que le vent tourne. Le réformer, c'est réformer toute une législation. C'est le chantier en cours. 


\section{Securitization} exceptions, par bursatilización, titularización ou securitización. Depuis le début des années 1980, de nombreuses lois régulent le développement du marché des titrisations en Espagne :

Loi 2/1981 (25 mars) sur la Régulation du marché hypothécaire (titrisation à l'actif) ; Loi 19/1992 (7 juillet) sur la titrisation hors bilan (crédits hypothécaires) ; Décret royal-Loi 3/1993 (26 février) sur la titrisation élargie à d'autres actifs non négociables ;

Loi 3/1994 (14 avril) sur la titrisation élargie à d'autres actifs (leasing, actifs liés aux activités des PME). Les fonds ainsi régulés sont appelés Fondos de Titulización de Activos (F.T.A.) ;

Décret royal 926/1998 (14 mai) qui régule les Fondos de Titulización de Activos (F.T.A.) et les Sociedades Gestoras de Fondos de Titulización (S.G.F.T.A).

41 En 2008, plus de la moitié des bons émis par les entités financières espagnoles sont aux mains d'investisseurs étrangers allemands, français, britanniques et américains. L'Espagne est le troisième pays émetteur ( 11,3 \% du total), derrière la Grande Bretagne $(38,2 \%)$ et l'Italie $(11,6 \%)$. On relève 321 occurrences du terme titulización durant le deuxième semestre 2007, 742 en 2008 et 440 en 2009 : 
Figure 10a. - Titulización, 742 occurrences en 2008 (source : Factiva).

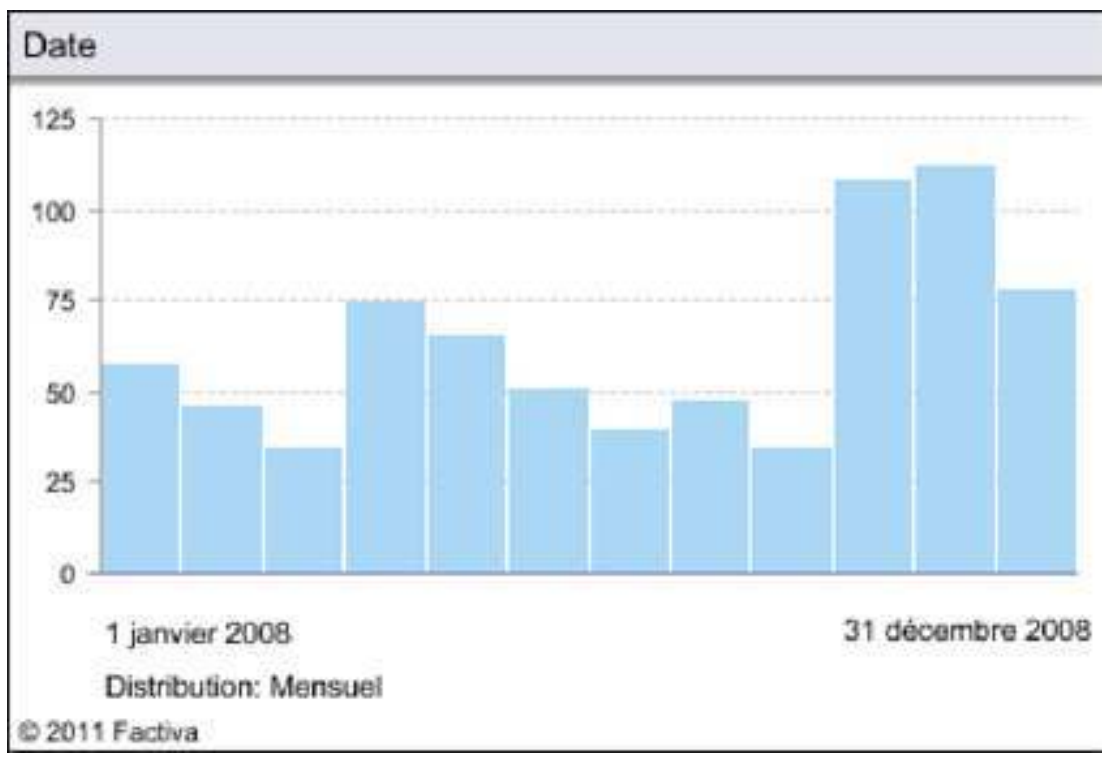

Figure 10b. - Titulización, 440 occurrences en 2009 (source : Factiva).

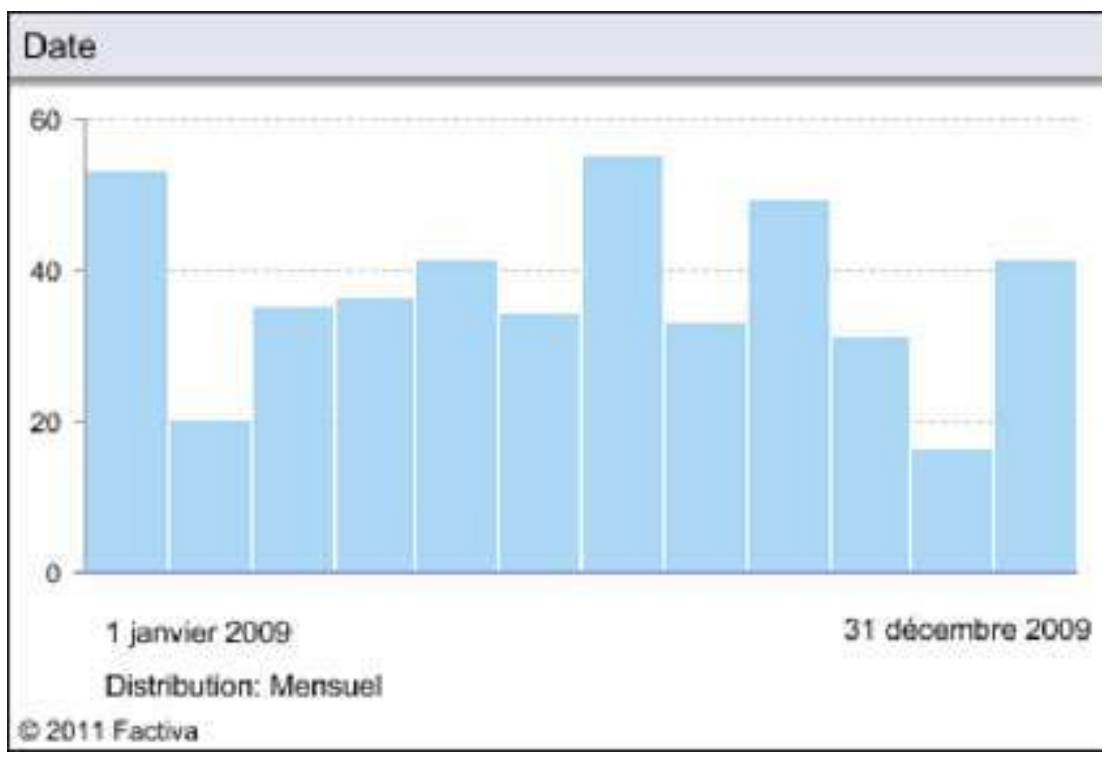

En mars 2007, la signature d'un accord de collaboration entre l'Instituto de Crédito Oficial (ICO, Institut du Crédit Officiel) et Ahorro y Titulización (Épargne et Titrisation) crée le plus grand fond de titrisation d'Europe (14099 milliards d'euros). La titrisation des hypothèques qui répartit le risque entre plusieurs investisseurs instille le doute sur la santé financière de certaines entreprises, les marchés se demandent qui sera la prochaine victime et la peur plane sur tout ce qui est considéré «à haut risque », subprime ou non. Les taux d'intérêt des bons et prêts émis par des entités financières jugées peu fiables vont naturellement grimper, on cherche à se débarrasser de ces titres qui ne trouvent ni marché ni acheteur : il n'y a plus de liquidité pour les bons corporatifs à haut risque et l'argent est plus cher. En Espagne, les titrisations disparaitront du marché le 4 mars 2010 32 . 


\section{Bad bank}

43 La traduction la plus courante est banco malo (22 occurrences entre le 29 janvier et le 6 novembre 2009) en opposition au banco bueno. La première occurrence isolée du terme anglais non traduit date du 4 octobre 2008 dans Expansión : « la formación de un bad bank al que los bancos pueden vender sus malos créditos ${ }^{33}[\ldots]$ ». Il faut attendre la fin du mois de janvier 2009 pour que la traduction banco malo apparaisse.

Figure 11. - Banco malo, 22 occurrences en 2009 (source : Factiva).

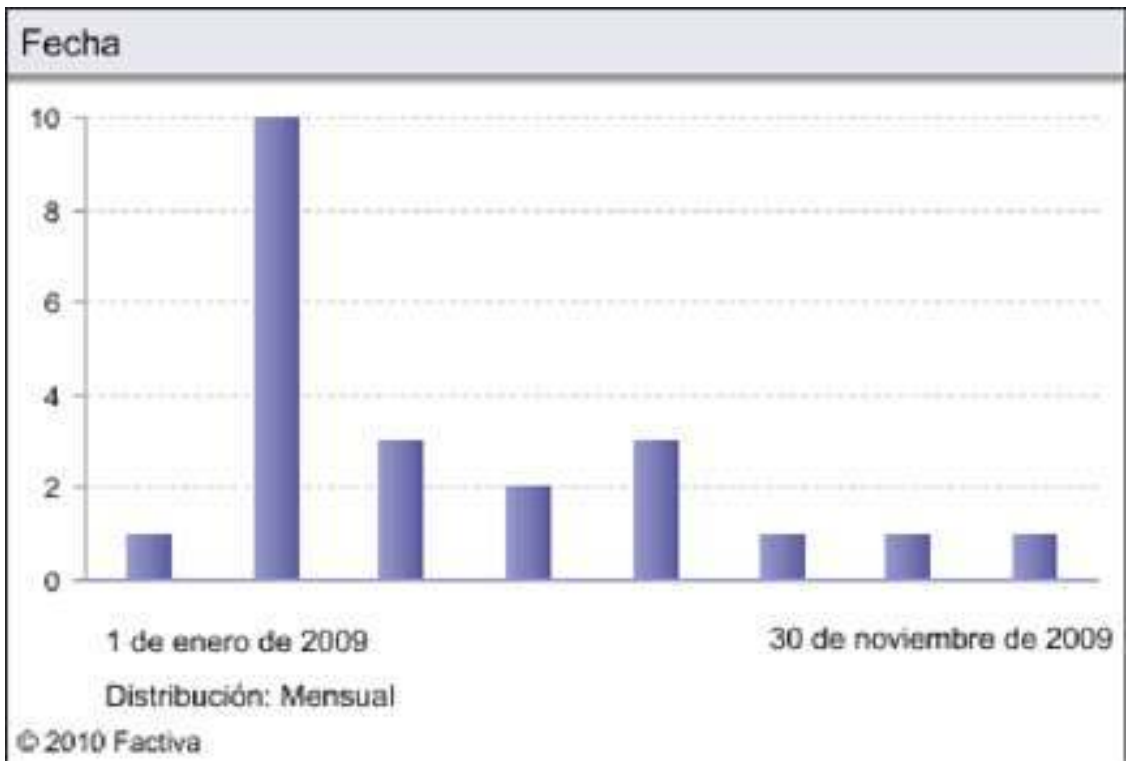

44 En Espagne, les agents économiques et le gouvernement sont défavorables à la création de ce type de structure de défaisance ${ }^{34}$ et opteraient plutôt pour la création d'un banco bueno: "crear un 'banco bueno' que se quede con los activos de una entidad dañada, como contrapropuesta al 'banco malo' del que se habla en Europa ${ }^{35}$ ». À de rares occasions , bad bank a été traduit par banco tóxico (3 occurrences en février 2009 ${ }^{36}$ ) ou banco defectuoso pour désigner le bad bank allemand): "En Alemania se ha utilizado recientemente un modelo más sencillo de banco defectuoso para gestionar los activos defectuosos de los Landesbanken ${ }^{37}$ ».

\section{Delinquency / Default}

Généralement traduit par morosidad, nous avons relevé 854 occurrences de ce terme entre 2004 et le premier semestre 2007: la presse est unanime pour célébrer l'absence de morosidad en Espagne : il n'y a pas de mauvais payeurs et un taux minimum historique à $0,522 \%$ est enregistré en 2004. Mais au cours du deuxième semestre 2007, la roue tourne et il apparait qu'une famille sur dix n'a pas de dettes. Nous avons relevé 583 occurrences du terme en 2007, 1172 en 2008 (soit 3,5\% de plus ${ }^{38}$ ) et 1398 occurrences en 2009. 
Figure 12. - Morosidad, 1172 occurrences en 2008 (source : Factiva).

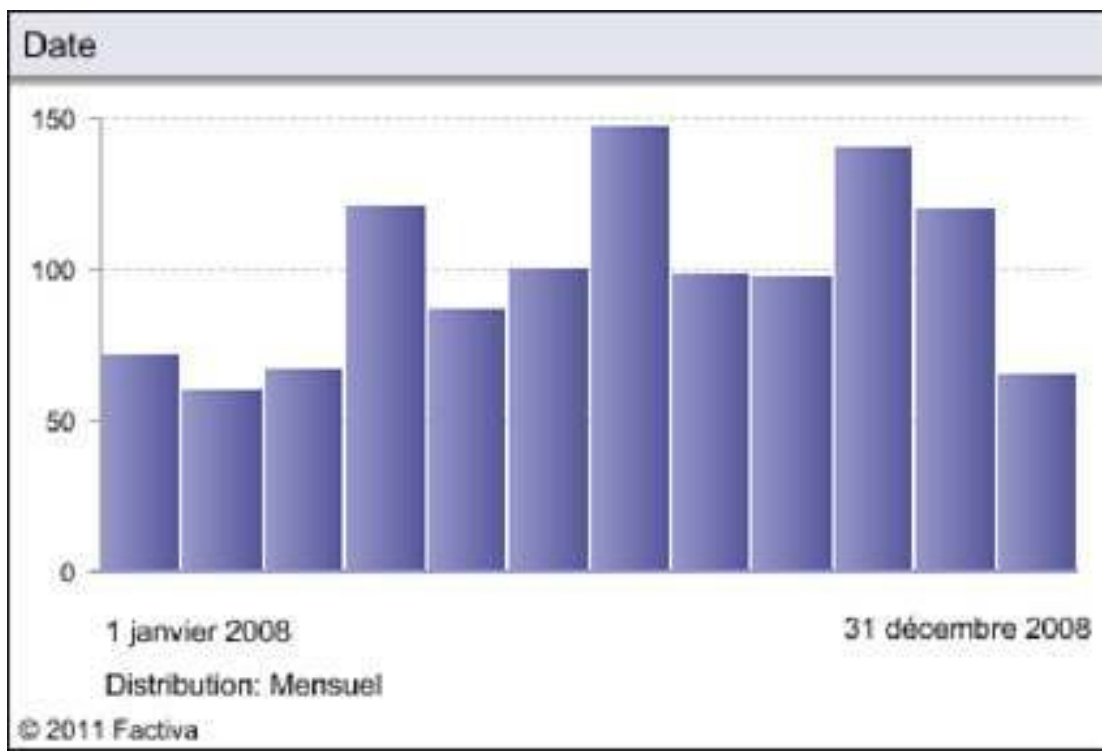

Figure 13. - Morosidad, 1398 occurrences en 2009 (source : Factiva).

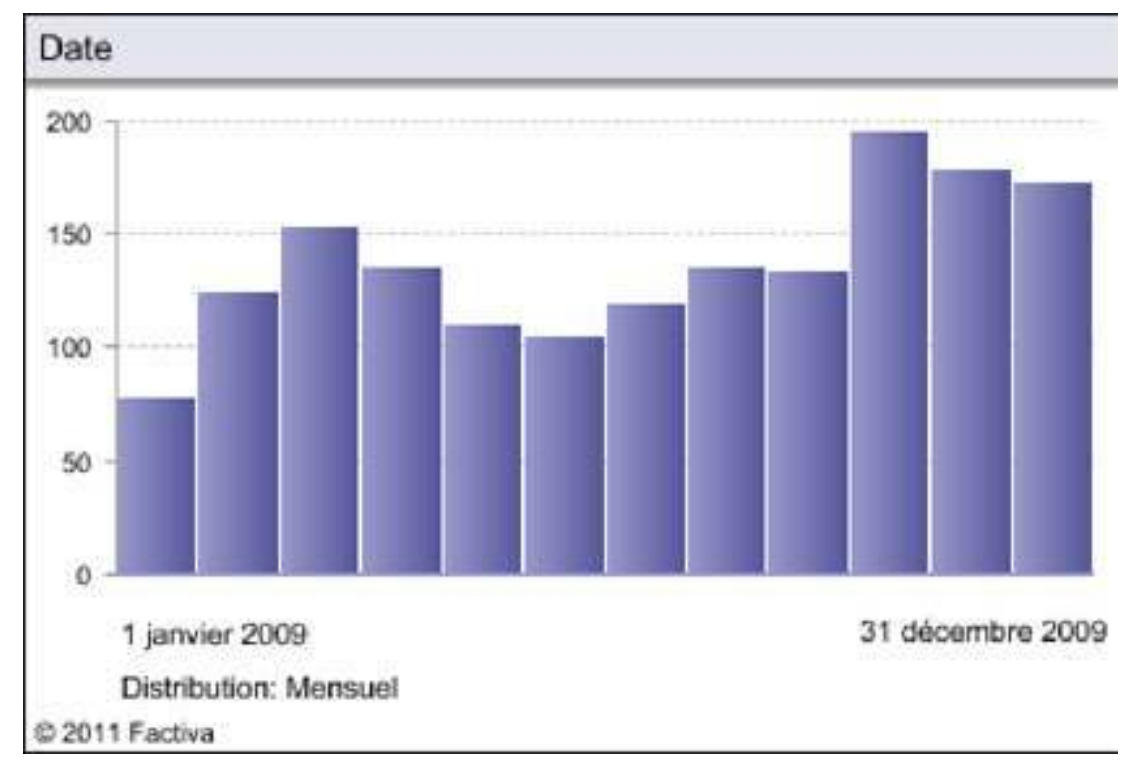

Toxic asset / TARP

Ce terme a connu de multiples traductions : Plan de rescate financiero (TARP); Programa de Alivio de Activos en Problemas (TARP); Plan de Alivio de Activos en Problemas (TARP); Plan de ayuda al sector financiero (TARP) ; Programa de alivio de activos problemáticos (TARP) ; Paquetes de rescate (TARP) dont un calque : Activos tóxicos.

L'acronyme TARP suit toujours entre parenthèses la définition du véhicule comme en témoignent les extraits suivants :

El segundo tramo de 350.000 millones de dólares (251.614 millones de euros) previsto en el programa de alivio de activos problemáticos (TARP) ${ }^{39}$.

Se sigue inyectando dinero del plan de rescate financiero, más conocido como TARP a este lado del Atlántico ${ }^{40}$. 
US\$200 mil millones disponibles del Programa de Alivio de Activos en Problemas (TARP, su sigla en inglés) para fomentar la contratación de trabajadores ${ }^{41}$.

La possibilité de nationaliser les banques est inscrite dans l'article 128 de la Constitution espagnole ${ }^{42}$ qui défend avant tout l'intérêt général et public ; dès la fin de l'année 2007, le gouvernement espagnol propose cette solution mais son application reste incertaine face aux réticences des acteurs économiques et sociaux ${ }^{43}$.

Figure 14. - TARP, 938 occurrences en 2008-2009 (source : Factiva).

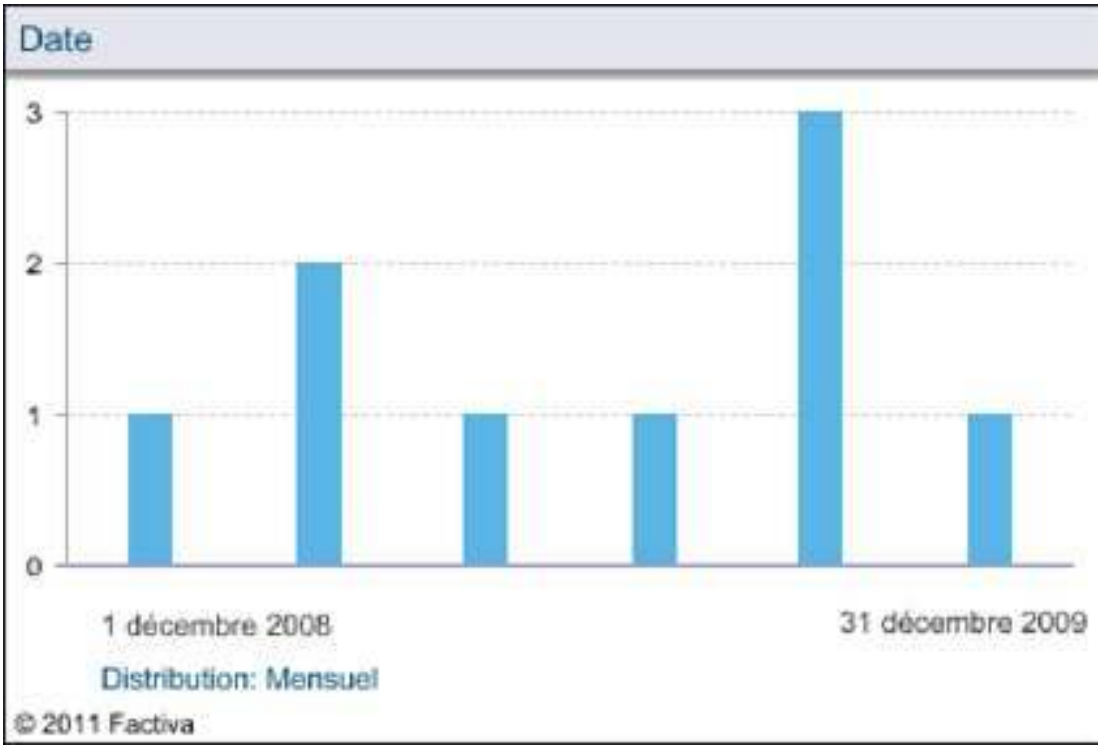

\section{SWAP, Credit default SWAP, CDS}

49 C'est probablement le terme qui enregistre le plus grand nombre de variantes. Si « seguros de impago » est le plus fréquent parmi les 197 occurrences $^{44}$ du terme, il n'est pas rare de trouver: intercambio de tipos, permutas crediticias, opción de compra a futuro, permuta de moneda, permuta financiera, crédito cruzado, crédito SWAP fallido, permutas cobertura por incumplimiento crediticio, permuta de créditos impagados, SWAPs de incumplimiento crediticio, permuta de divisas, acuerdo de recompra, préstamo de divisas con pacto de recompra. 
Figure 15. - SWAP, 197 occurrences de 2007 à 2009 (source : Factiva).

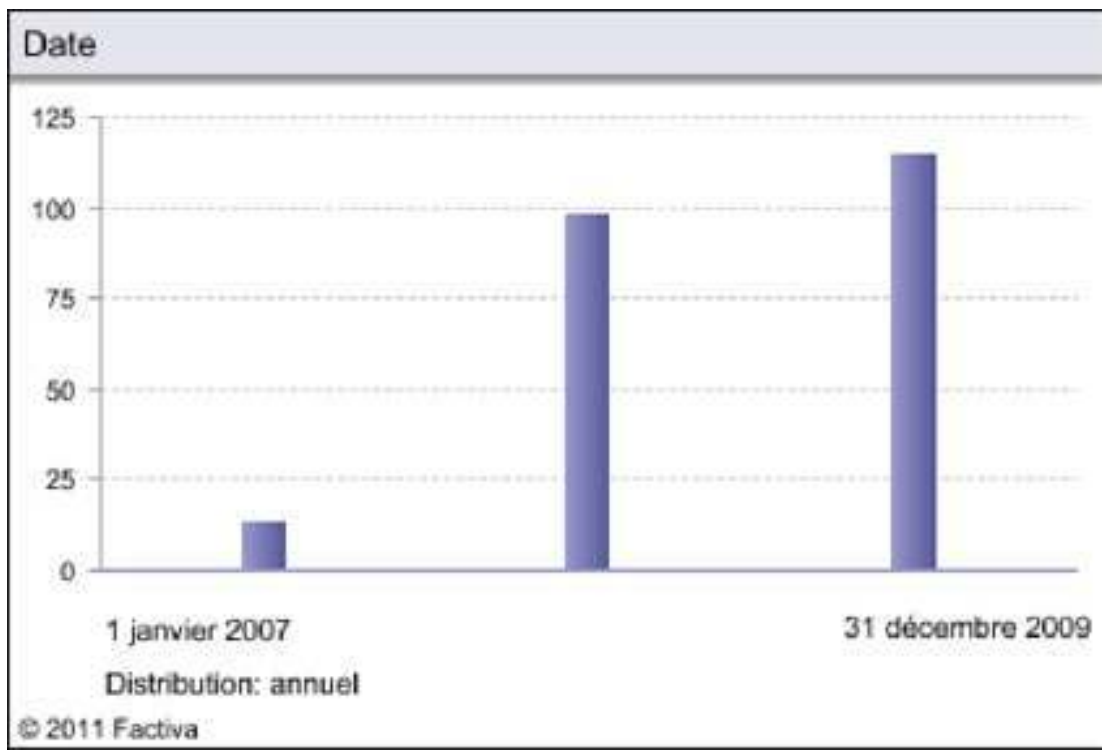

À l'été 2007, la chute brutale des indices calculés à partir des CDS a été l'un des premiers indicateurs du début de la crise financière. Créé en 1994 par Blythe Masters, le Credit Default Swap (CDS) est un contrat de protection financière par lequel un vendeur de protection s'engage, contre le paiement d'une prime et en cas d'événement affectant la solvabilité d'une entité de référence, à dédommager l'acheteur. Se négociant de gré à gré, ces contrats de protection financière entre acheteurs et vendeurs échappent au contrôle des pouvoirs publics et permettent ainsi de contourner toutes les règles prudentielles, d'autant que sur le plan des flux financiers, ils sont travaillés hors bilan et hors bourse. Les CDS, produits dérivés de crédit, sont considérés comme l'une des causes de la chute, le 15 septembre 2008, de l'American International Group (AIG). Largement vus comme l'une des sources de la diffusion incontrôlée des risques de crédit et donc de la crise financière (la plus grave depuis 1929), les CDS sont dans le collimateur de ceux qui veulent affermir les réglementations et resserrer le contrôle des activités bancaires. En Espagne, et notamment depuis 2004, les agents financiers (banques, hedge funds) ont largement utilisé cet outil de couverture des risques qui a fini par dominer le marché des produits dérivés de crédit, à hauteur de $73 \%$.

Entre 2007 et 2008, le CDS à 5 ans s'est tendu de 5 points de base à $40 \mathrm{pb}$ (de 1 à $12 \mathrm{pb}$ pour l'Allemagne et de 1 à $15 \mathrm{pb}$ pour la France) comme en attestent les graphiques suivants : 
Figure 16. - CDS Espagne (source : Institut Eurostat).

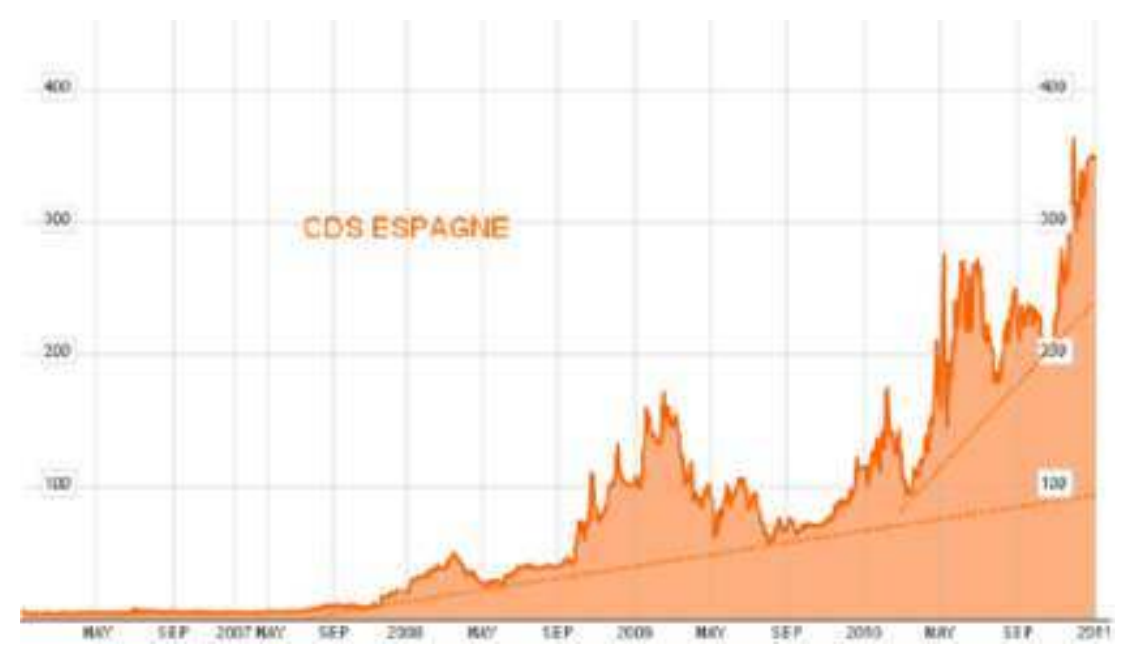

Figure 17. - CDS Europe - États-Unis (source : Institut Eurostat).

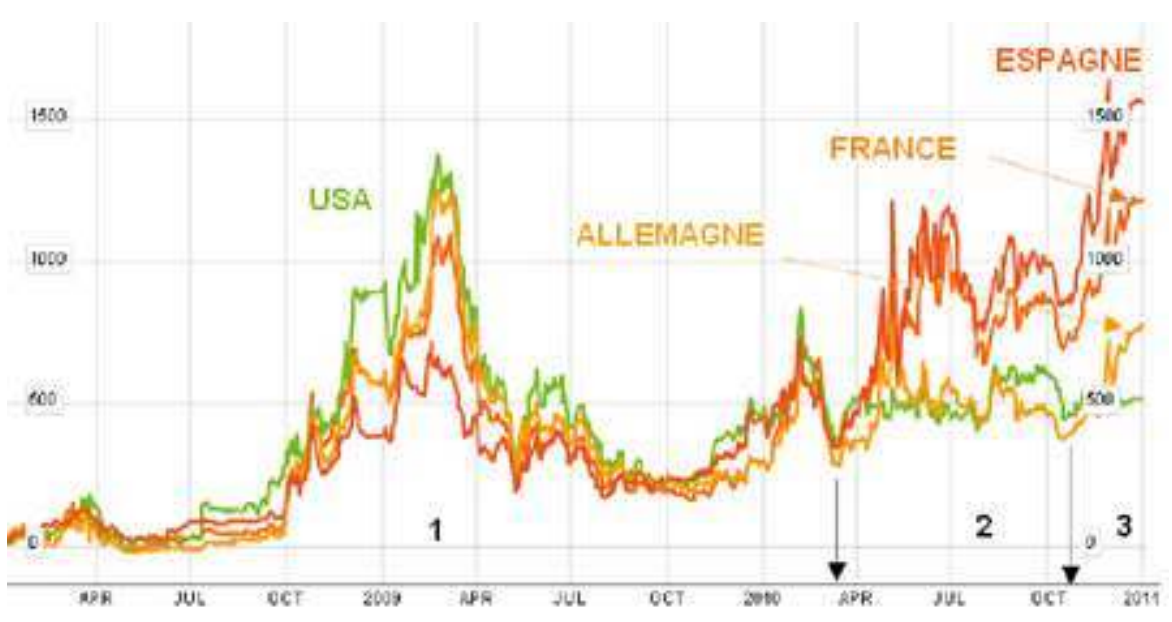

En 2009, la prime sur l'Espagne a été multipliée par plus de 2 depuis le lancement de l'indice, la situation se dégrade sérieusement et l'Espagne apparaît comme le pays le plus risqué.

\section{Hedge fund}

Créé aux États-Unis en 2003, la première occurrence de hedge fund (fonds d'investissement non cotés à vocation spéculative) apparaît sous forme de calque, sans explication aucune, dans un article intitulé « Un millón para el mejor », publié par le périodique Expansión, le 29 janvier 2003 : "creando un hedge fund que explote esa estrategia ${ }^{45}$ » Il faudra attendre la fin de l'année 2003 pour trouver la première traduction-adaptation: "los fondos de inversión denominados "hedge fund" - o también de inversión alternativa o de alto riesgo ${ }^{46}$ ". À partir de mars 2007, s'il n'est pas rare de trouver fondos de gestión alternativa y alto riesgo, fondos especulativos, ou fondos de inversion libre, le terme le plus fréquemment employé tant dans la presse spécialisée que généraliste est « hedge fund (fondos de alto riesgo) » avec sa variante "hedge fund (fondos de cobertura)». Les hedge fund ont envahi le marché espagnol en 2006 suite à la bulle internet ${ }^{47}$ et le premier hedge fund espagnol a été créé le 10 novembre 2006 par BBVA ${ }^{48}$. Cet instrument financier a suivi la même dérive que les 
SWAPs : on passe de l'assurance à la spéculation puisque l'on peut parier sans détenir les créances :

Los instrumentos del nuevo capitalismo americano, los hedge funds y el private equity, con sus prácticas de troceamiento de empresas y reducción de empleo, dirigidas a lograr su objetivo básico : la búsqueda de elevadas rentabilidades a corto plazo, del orden del $25 \%{ }^{49}$.

On enregistre 29 occurrences de hedge fund entre 2004 et 2005, 50 en 2006 et 172 entre 2007 et 2009, avec un pic en 2007.

Figure 18. - Hedge fund, 172 occurrences de 2007 à 2009 (source : Factiva).

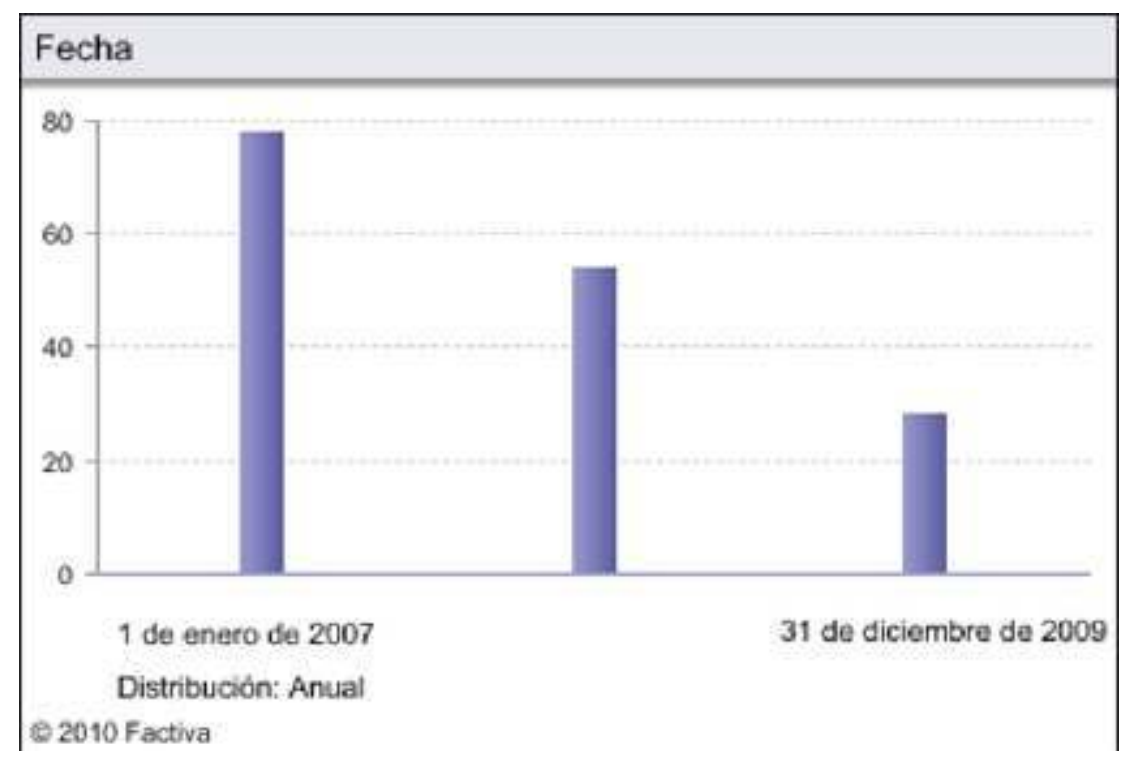

Recession

Traduction : recesión, desaceleración.

Du fait des élections électorales de mars 2008 et d'un optimisme volontairement aveugle, le terme recession, généralement traduit par recesión ou desaceleración, a été banni du discours officiel. Les medias espagnols ont souvent évoqué non pas la force tranquille de Zapatero mais son ataraxie. Jusqu'au début de l'année 2009, le gouvernement parle de «desaceleración» (ralentissement ${ }^{50}$ ) ou de son euphémisme «incidencias en el crecimiento " (incidences sur la croissance) qui n'a rien d'inquiétant étant donné le taux de croissance élevé du pays durant les dernières années $(3,5 \%$ en moyenne et $4 \%$ en 2006). L'économie poursuit donc sa croissance à un taux plus faible ( $2 \%$ officiellement alors qu'en réalité il est à $0,5 \%{ }^{51}$ ) durant ce que le président appelle «la brève parenthèse » qui sera suivie de la « recuperación » (la reprise) promise pour la fin 2009, avec un retour à $3 \%$ de croissance.

Deux discours s'affrontent dans le même temps historique. Le discours officiel est catégorique : España va bien, [...] Papá Estado tiene la hucha llena, tras varios años de superávit ${ }^{52}$ ; l'économie espagnole fait pâlir de jalousie ses voisins européens; les institutions financières sont un modèle du genre; la rigueur dans la gestion est citée en exemple dans le monde entier et si une légère houle s'est installée au printemps 2008, il n'y a aucune raison de s'inquiéter; le vaisseau est solide et il faut se méfier de la tendance à l'exagération : 
«El presidente del Gobierno, José Luis Rodríguez Zapatero, afirmó hoy que "no hay que ignorar que pasan cosas" en la economía española, en referencia al deterioro de los índices macroeconómicos en los últimos meses, pero hizo hincapié en que "no hay que exagerar" 53 ", Expansión, 8 février 2008.

"Almunia quita hierro y dice que la situación no es dramática » [Almunia minimise la situation qui est loin d'être dramatique, selon lui], Gaceta de los Negocios, 24 mai 2008.

«El modelo español es valorado como el más robusto " [Le modèle espagnol est cité comme le plus robuste], Hoy, 28 septembre 2008.

"Zapatero afirma que el sistema financiero español "es el más sólido del mundo" " [Zapatero affirme que le système financier espagnol est "le plus solide au monde"], La Verdad, 25 septembre 2008.

Le discours de certains économistes étrangers et espagnols est, quant à lui, bien moins rassurant. Dès 2004, la Société générale française prévoit une crise en Espagne liée à la bulle immobilière :

«Hay una burbuja inmobiliaria, asegura el banco francés. Las entidades financieras españolas asumen un riesgo mucho más alto que las del resto de Europa al conceder préstamos hipotecarios. La economista jefe de Société Générale, Véronique Riches-Flores, advierte sobre los efectos de la burbuja inmobiliaria ${ }^{54}$. "

Dès les premiers mois de 2007, la récession en Espagne est annoncée par le FMI, Bruxelles et la COFACE et relayée par une partie de la presse ${ }^{55}$. Mais il n'y a pas pire sourd que celui qui ne veut pas entendre et il faudra attendre 2009 pour que les termes desaleración (ralentissement) et recesión (récession) soient majoritairement employés, parallèlement à l'annonce de la prochaine recuperación (reprise).

Figure 19. - Desaleración, 8098 occurrences en 2009 (source : Factiva).

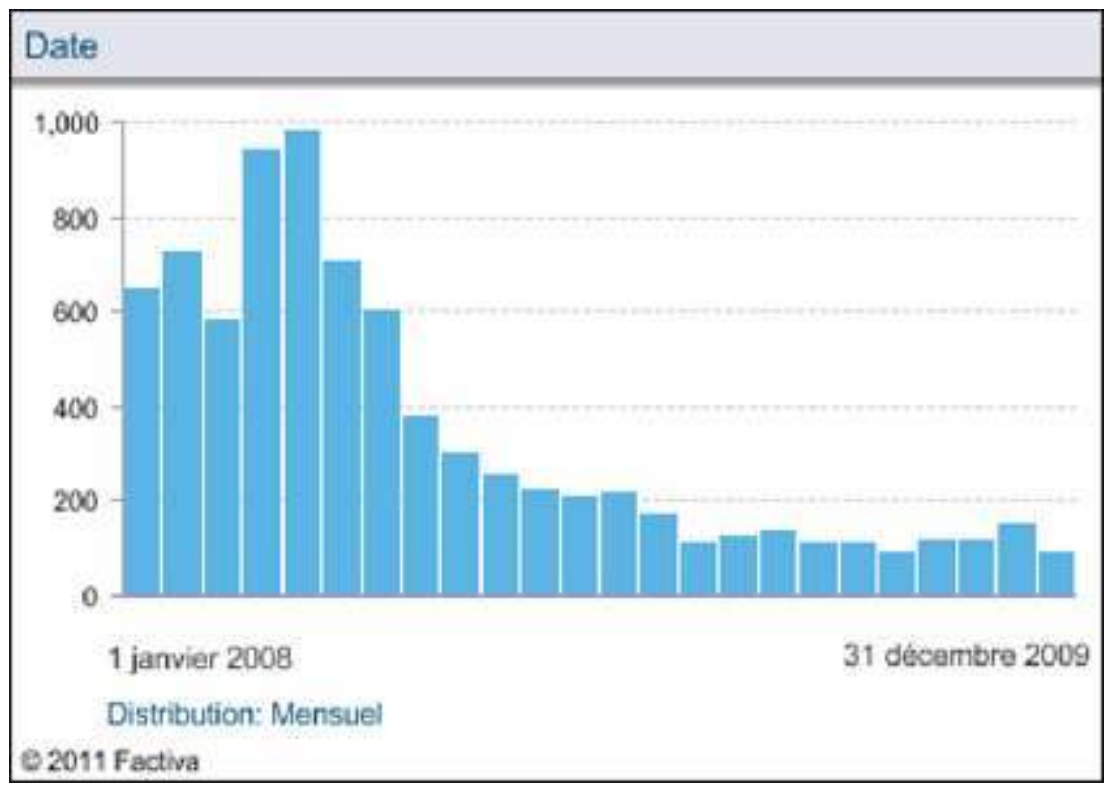


Figure 20. - Recesión, 12205 occurrences en 2009 (source : Factiva).

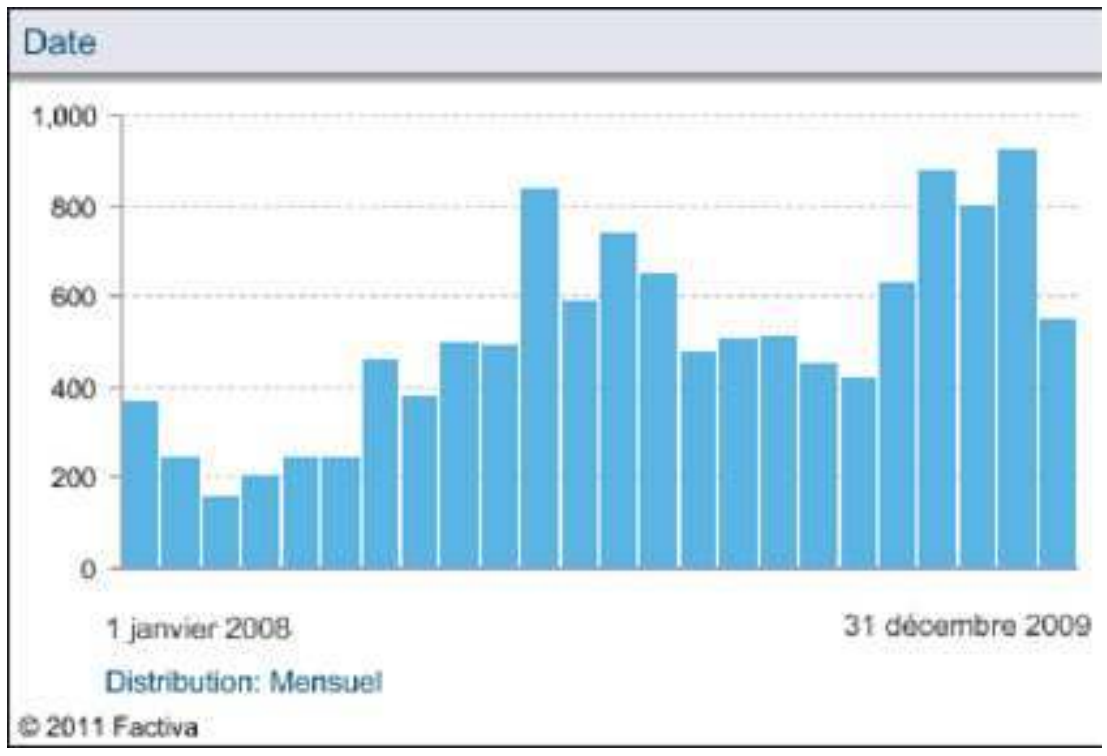

Figure 21. - Recuperación, 10581 occurrences (source : Factiva).

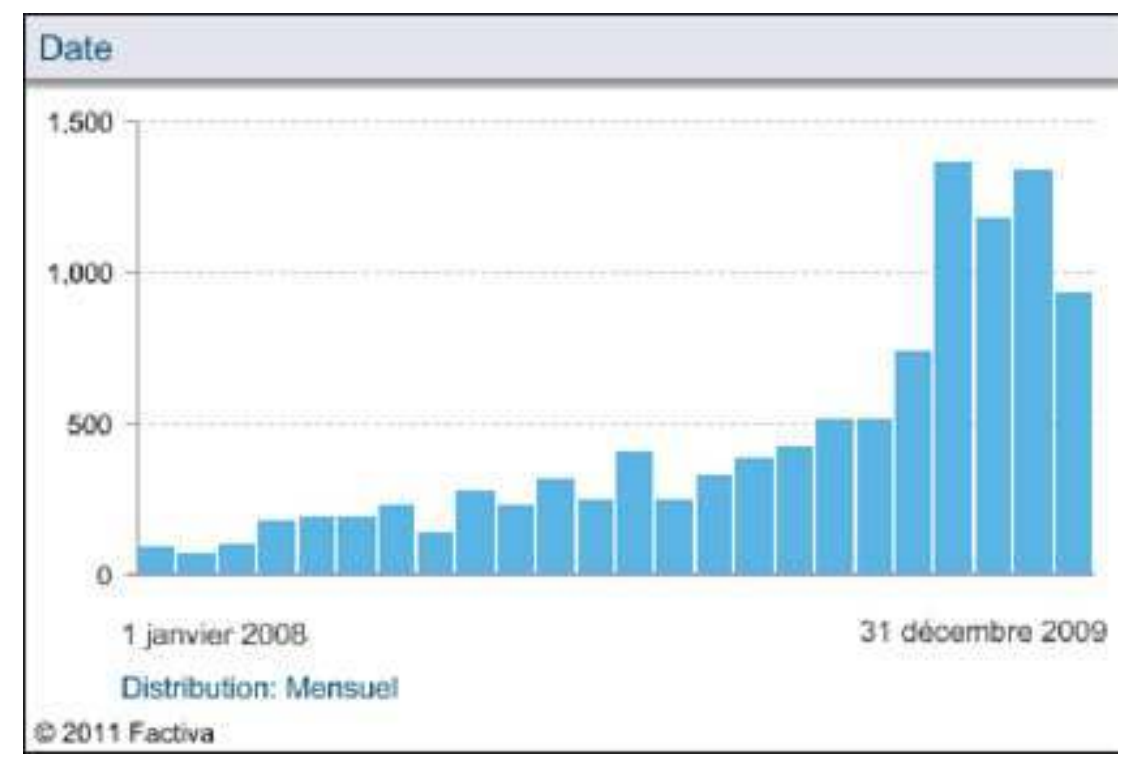

\section{Les médias et la crise}

En Espagne, les années 1990 sont caractérisées par le boom de l'information économique générée par le bien-être économique, l'expansion du commerce international (potentialisé par le phénomène discuté de la mondialisation) et la consolidation du " capitalisme populaire » caractérisé par la participation de millions de familles sur les marchés boursiers. La presse économique est donc aux premières loges pour raconter et rendre compte de cette nouvelle donne. Face à la demande croissante d'informations de la part d'un public toujours plus nombreux, on a non seulement vu fleurir de nouveaux périodiques spécialisés mais la plupart des quotidiens d'information générale ont renforcé leur section « Économie » (en personnel, en pages et en qualité) notamment par 
le biais des «Suplementos salmón » (suppléments saumon du fait de la couleur des pages). Par extension, la presse financière et économique est aujourd'hui appelée «la presse saumon ».

61 La presse financière et économique est abstraite et complexe. Elle exige une grande rigueur dans le maniement des concepts et un haut niveau de formation pour une interprétation correcte. Le rôle des journalistes économiques est de servir d'intermédiaire entre le langage spécialisé des experts et le langage compréhensible par le grand public en essayant de garder dans ce processus de requalification sémantique toute la rigueur nécessaire. Bien qu'elle soit difficile à comprendre par le grand public, l'économie touche néanmoins chaque citoyen dans sa vie quotidienne et chacun est amené à se former une opinon à partir du simple bon sens, à défaut de maîtriser les mécanismes. Ceci étant, on ne peut expliquer un phénomène économique tel que la bulle immobilière sans le mettre en regard avec d'autres variables comme la baisse des taux d'intérêt, l'évolution des revenus, la baisse du taux de chômage ou la tendance démographique du pays. Ce haut niveau d'abstraction et de causalité dote l'économie d'un caractère spéculatif et interprétatif que l'on retrouve irrémédiablement dans la presse. Par ailleurs, l'objectif des journalistes est double: informer certes, mais convaincre surtout le lecteur que toutes les informations publiées sont objectives et d'autorité reconnue.

Dans les articles de presse économique et financière, les commentaires et les prévisions jouent un rôle important (Miecznikowski, Rocci et Zlatkova, 2010). Le journaliste part de données factuelles communiquées par les institutions, il sélectionne et analyse l'information à partir d'une interprétation prospective, en partie subjective, qu'il enchasse dans un discours argumentatif émotionnel auquel le lecteur sera réceptif. La dispositio $^{56}$ se caractérise par une organisation descendante: un sommaire résumant la nouvelle qui sera développée dans l'histoire au niveau de l'événement principal et des actes subordonnés qui s'insérent à différents degrés d'intégration. Le style et la rhétorique (elocutio) sont, bien entendu, déterminants dans la construction du récit. Par rapport aux autres thématiques de presse, l'enjeu est ici particulièrement important puisqu'il engage des décisions de consommation, d'investissement, d'épargne et de vote citoyen, l'information économique étant intimement liée à la popularité d'un gouvernement. Enfin, le développement des pages financières est loin d'être anodin : « s'il n'est pas directement imputable à une prise de position idéologique, il légitime le point de vue des actionnaires de plus en plus omniprésents dans le champ journalistique d'une part et d'autre part, il participe à une sorte de financiarisation des esprits » (Lebaron, 2001).

Le dépouillement des périodiques nous a permis de dégager deux grandes catégories de textes économiques: les articles à vocation informative dans lesquels le journaliste rapporte de façon neutre le discours des acteurs de l'économie (marquage explicite des discours cités, discours rapportés, directs ou indirects) et ceux dans lesquels l'auteur a recours aux incises (parenthèses et tirets) qui servent soit à organiser l'information soit à résoudre un problème de compréhension (traduction ou transcodage) soit à introduire une dimension subjective en donnant son point de vue. Dans les deux cas, la situation de communication est plurilogale de par la diversité des locuteurs impliqués (mais aussi des genres, des localisations): le médiateur, le public des lecteurs, la communauté scientifique qui fournit les sources, des ministres, des économistes, des industriels, des 
syndicalistes, ou d'autres "experts", qui filtrent, reformulent ou dissimulent le discours scientifique.

Depuis les années 2000, et suite à l'éclatement des différentes bulles, un certain désintérêt doublé de méfiance vis-à-vis de la presse s'est installé chez le citoyen moyen. Les journalistes peinent à expliquer et interpréter la réalité économique pour la rendre accessible à tous, parfois par manque de formation spécifique dans ce domaine. Ils ont donc recours à des stratégies d'information de substitution comme :

la personnalisation de l'économie pour toucher le grand public et conférer un intérêt immédiat au sujet d'actualité économique ; c'est ainsi que le récit de l'augmentation du taux d'intérêt énonce les effets de cette mesure sur l'épargne et l'évolution des hypothèques de personnes réelles, raconte les drames engendrés et dénonce les duperies ${ }^{57}$;

l'analyse en tant que complément d'information est une pratique qui remonte au XIX $\mathrm{x}^{\mathrm{e}}$ siècle ; les périodiques font appel aux experts pour les articles spécialisés, le lecteur y gagne en clarté et en rigueur et dispose du cadre d'interprétation nécessaire pour comprendre les faits. Néanmoins, de nos jours, on ne peut exclure le risque que cette tradition discrédite la compétence professionnelle des journalistes spécialisés.

\section{Procédés discursifs et champs lexicaux de la crise}

\section{Procédés discursifs}

Dans leur stratégie de captation médiatique, les journalistes utilisent une large gamme de procédés qui «consistent à mettre en scène l'information, de telle sorte que celle-ci participe d'un spectacle qui, comme tout spectacle, doit toucher la sensibilité du spectateur " (Charaudeau, 1994: 17). La crise, manifestation désordonnée dont l'intelligibilité échappe aux acteurs et spectateurs, sera décrite comme un récit (ou un drame) avec un début, un déroulement et une fin et analysée comme une maladie avec ses causes, ses modalités, son extension, ses effets, ses diagnostics, ses pronostics, ses résultats.

Dans le discours de presse argumentatif qui se veut rationnel et objectif, nous avons relevé de très nombreux connecteurs de cause et d'opposition (por lo tanto, aunque, pese a ello, a pesar de lo cual, o de lo contrario, pues resulta que, aun así, etc.), des connecteurs de démonstration (pues, entonces, ahora bien, pero, pues bien, etc.), de tentatives d'explication ( por ello, de ahí que, es decir, esto es, dicho de otro modo, así que, etc..$\left.^{58}\right)$ qui, sur le plan sémantique, témoignent d'une démarche évaluative implicite. Le discours argumentatif fait la part belle à la recherche de rationalité qui tente de masquer le terrain radicalement incertain sur lequel les agents économiques essaient de placer quelques repères simples et partagés pour sauver les apparences. Comme le souligne Frédéric Lordon, « la rationalité des marchés financiers est une rationalité empêchée, incapable de se conformer au modèle de la rationalité dite standard, et celle des grands patrons une rationalité dévoyée par des considérations et des objectifs politiques de puissance: grossir à tout prix pour ne pas être dévoré par les concurrents » (Lordon, 2002: 211). On retrouve ici un élément fondamental de la critique keynésienne de l'école néoclassique à propos de la spéculation boursière : mieux vaut avoir tort avec tout le monde que raison tout seul et pour ce faire, il faut remettre au cœur de l'analyse économique la psychologie collective, les croyances, les anticipations, les conventions et la confiance. 
Les formes superlatives et les hyperboles sont récurrentes (nous traduisons: crise considérable, crise exceptionnelle, ampleur inouïe, extraordinaire, formidable, spectaculaire, brutal, excessif, catastrophique, désastreux, apocalyptique, effroyable, massif, extraordinaire, impressionnant, essentiel, gigantesque, absolu, considérable, intense, colossal, astronomique, faramineux) afin de potentialiser l'effet de dramatisation du discours de crise anxiogène. La rapidité et l'intensité du choc étant les deux principaux vecteurs du discours sur la crise, le recours aux adverbes d'intensité (nous traduisons : très, plus, de plus en plus, encore, fortement, particulièrement, violemment, surtout, intensément, etc.) et aux adverbes de temps pour contextualiser la crise sur l'échelle temps (naissance, évolution, pic, fin prévue) n'est pas surprenant. Enfin, au niveau de la ponctuation, si les deux points, les virgules, les guillemets distanciateurs et les parenthèses encadrent très souvent un élément d'information apposé, l'évolution de l'emploi des guillemets sur le terme financier anglais est particulièrement intéressante : durant le deuxième semestre 2007, ils servent à marquer les premières occurrences du terme pour témoigner ensuite d'une certaine transparence dans la dénomination et au cours de l'année 2008, leur abandon progressif atteste clairement que la formule cesse d'être perçue comme un emprunt pour intégrer le lexique financier. L'exemple le plus marquant est celui de las subprime.

\section{Champs lexicaux}

Quant aux champs lexicaux de la crise, nous avons relevé dans le corpus de la presse espagnole une grande polymorphie des références à la crise. Si c'est avant tout une crise « financière » (5001 occurrences avec un pic en 2008), c'est aussi une crise immobilière (184 occurrences avec un pic en 2008), une crise du crédit (658 occurrences avec un pic en 2008 et une chute brutale en 2009), une crise des subprimes (461 occurrences), une crise bancaire (119 occurrences avec un pic en 2009), une crise systémique (42 occurrences), une crise boursière ( 2261 occurrences avec un pic en $2008^{59}$ ), une crise de liquidités (519 avec un pic en 2008 et une chute nette en 2009), une crise économique (12 695 avec un pic en 2009), une crise sociale (71 occurrences essentiellement en 2009), une crise mondiale (424 occurrences avec un pic en 2009), une crise globale (462 occurrences), une crise actuelle (639 occurrences avec un pic en 2009) sans oublier la fréquente comparaison à la crise de 1929, procédé discursif qui frappe les esprits en dramatisant, à tort ou à raison, la situation (390 occurrences avec un pic en 2009).

L'analyse du discours de presse nous a permis de dégager trois champs lexicaux récurrents : le champ lexical métaphorique pour désigner la crise sans la nommer, pour frapper les esprits ; le champ lexical psychologique pour associer des émotions à la crise, pour susciter des émotions et potentialiser l'impact; le champ lexical axiologique pour juger la crise économique et sociale.

\section{Champs lexicaux métaphoriques}

70 Selon l'approche classique et en suivant Aristote, la fonction de la métaphore est de donner une idée de la manière dont quelqu'un perçoit la réalité ; cette réalité subjective ne correspond pas à la réalité objective (Taverniers, 1996). Dans l'approche moderne, représentée par Lakoff et Johnson (1985: 13), les métaphores font partie de notre système conceptuel, c'est-à-dire du système "qui nous sert à penser et à agir ». De ce fait, la métaphore n'est jamais gratuite : elle occupe une place considérable au niveau langagier 
- dans nos conversations et dans de nombreux textes - et elle constitue une partie souvent essentielle de nos actions et de nos pensées. Toujours selon Lakoff et Johnson, «l'essence d'une métaphore est qu'elle permet de comprendre quelque chose (et d'en faire l'expérience) en termes de quelque chose d'autre » (Lakoff et Johnson, 1985 : 15). Le rôle premier de la métaphore dans notre conceptualisation étant de faire voir, elle apparaît comme mécanisme de médiation et de projection entre un monde réel et un monde projeté (Vercruysse, 1995 : 65). C'est donc tout à la fois un phénomène langagier mais aussi un "mécanisme de pensée humain » (Vercruysse, 1995 : 66) dont les fonctions discursives ont un effet majeur de transformation et d'amplification du sens. Le discours de presse a largement utilisé la force explicative et persuasive de la métaphore pour véhiculer des opinions et des jugements en faisant l'économie de l'explication mais en convoquant le rôle de la mémoire dans l'explication ou plus exactement le rôle des mémoires collectives qui se construisent autour des différentes familles d'événements. Dans le domaine des métaphores, et pour connoter les notions de dérèglement, de déséquilibre et de catastrophe, les médias ont eu recours à trois champs sémantiques : celui du climat (borrasca, tormenta, vendaval, ciclón, hurracán, etc., 8039 occurrences ${ }^{60}$ ), celui du chaos (debacle, desastre, catástrofe, tsunami, terremoto, etc., 1075 occurrences $^{61}$ ) et de la médecine (indigestión, contaminación, contagio, hemoragia, metástasis, cáncer, gangrena, locura, ahogo, asfixia, pandemia, parálisis, etc., 1568 occurrences $^{62}$ ).

\section{La métaphore du climat et de la catastrophe naturelle pour décrire le déclenchement de la crise.}

71 La métaphore météorologique est la métaphore préférée des journalistes car elle peut être filée à loisir. Dans la presse espagnole, elle se caractérise par la gradation de la gravité des termes qui vont avoir un fort impact psychologique sur les lecteurs pour symboliser la perte de contrôle et les bouleversements engendrés par la crise : de gros nuages à l'horizon (nubarrones), l'orage (la tormenta) qui éclate aux États-Unis, la tempête ( el vendaval) qui se déchaîne sur l'Europe, l'ouragan (el huracán) qui fait vaciller le système, le cyclone (el ciclón) qui ravage l'économie ${ }^{63}$. Les victimes de ces phénomènes inévitables, incontrôlables et destructeurs sont les particuliers, la Bourse, les banques, les marchés, les prix et l'investissement. Incapable de contrôler le climat, l'homme est condamné à attendre que la tempête se calme. Il n'y a ni responsable ni cause ni remède préventif.

Il en va de même pour la métaphore de la catastrophe naturelle caractérisée par sa vitesse et sa force destructrice. Le vocabulaire employé va privilégier les métaphores sismiques: le tremblement de terre financier (terremoto financiero, 111 occurrences), l'épicentre d'un tsunami apocalyptique (el epicentro de un tsunami apocalíptico, 154 occurrences), la magnitude du séisme, les secousses, les répliques, les ondes, les failles qui se creusent, le chaos (la magnitud del seismo, las sacudidas, las réplicas, las ondas, las fallas se ensanchan, el caos, 378 occurrences).

\section{La métaphore maritime pour décrire le système financier espagnol.}

73 De 2007 au début de l'année 2009, le discours officiel présentait le système financier espagnol comme un des vaisseaux les plus solides au monde, insensible à la houle qui agite les eaux de la finance et tout à fait apte à résister aux éventuelles tempêtes. Le Capitaine sifflote alors que les Espagnols rament. En 2009, lorsque le gouvernement sort du déni et les medias de l'incertitude, le discours devient clair : les banques chavirent, le 
secteur financier est démâté, l'économie se noie, la chaloupe est emportée par l'ouragan. La métaphore partielle de la submersion est intéressante car elle attribue la catastrophe non pas à une erreur de pilotage mais à la hausse soudaine et incontrôlable de l'eau, au déluge qui s'abat et qui fait des victimes: la Bourse, le système financier, les autorités, l'économie.

\section{La métaphore de la maladie pour qualifier la durée de la crise et ses répercussions sur le système financier. La métaphore de l'asphyxie pour décrire les effets de la crise sur les victimes.}

74 La conception de l'économie comme un organisme vivant existe depuis le XVIII ${ }^{\mathrm{e}}$ siècle lorsque François Quesnay, médecin et chirurgien de Louis XV, se basa sur son expérience en tant que chirurgien pour projeter l'image du mouvement sanguin sur la circulation économique. Mais c'est à partir du XIX ${ }^{e}$ siècle que l'organicisme, la nouvelle doctrine de Schäffle et Rodbertus, assimile de façon suivie le système économique à un corps vivant. À partir de la métaphore lexicalisée du corps vivant, la première métaphore dérivée pour décrire la crise est celle de la contagion de la " grippe américaine ${ }^{64} »$ : comme une maladie contagieuse ou un virus (symptômes, fièvre), la crise financière se propage telle une hémorragie, elle infecte et gangrène les banques les unes après les autres. Les cataplasmes et analgésiques sont inneficaces, les métastases se développent et envahissent le système, l'embolie sera mortelle. Faute de diagnostic, et donc de protocole thérapeutique, la paralysie gagne le système défectueux car dans une économie saine, les marchés de crédit sont actifs et en mouvement. La psychose s'installe et la folie s'empare des marchés et des esprits. Si l'image de la maladie est porteuse d'espoir de guérison, la métaphore de la mort annihile toute possibilité de récupération de par son caractère inéluctable: les métaphores de l'étranglement financier et de l'asphyxie sont très fortes car la privation d'oxygène empêche la survie de l'organisme vivant qui cesse de fonctionner. En outre, dans la mentalité collective espagnole, l'asphyxie et la strangulation ne sont pas de simples métaphores de la mort surtout lorsqu'elles s'appliquent aux victimes de la crise, aux citoyens: elles convoquent la peine capitale, l'exécution par le garrot et de façon plus large, le meurtre qui implique la double existence de responsable et de victime. Les métaphores de la mort rendent les lecteurs conscients de la gravité de la situation économique et de sa nature irréversible: l'étouffement, l'apnée, l'asphyxie, la strangulation, autant de termes qui signalent la gravité d'une crise qui relève davantage des médecins urgentistes que des médecins généralistes.

Quelques exemples relevées dans la presse spécialisée et généraliste pour fonder nos propos:

«La larga enfermedad que está suponiendo la crisis económica » [La longue maladie que la crise économique implique],

«La crisis económica se parece a la gripe A: una pandemia de la cual se sale y que sólo resulta mortal para quienes tenían otras dolencias previas » [La crise économique est semblable à la grippe $\mathrm{A}$ : une pandémie dont on peut guérir et qui n'est mortelle que pour ceux qui souffrent d'autres pathologies],

"Las autoridades económicas se muestran incapaces para determinar la extensión de la gangrena, la terapia a aplicar y la duración del mal » [Les autorités économiques sont incapables de déterminer l'étendue de la gangrène, la thérapie adéquate et la durée du mal],

«El cáncer letal de nuestra crisis económica » [Le cancer létal de notre crise économique], 
"La sintomatología de la enfermedad: estenosis aguda de los mercados financieros, severa arritmia de los equilibrios globales, trombosis en las vías arteriales del dinero por la toxicidad de la deuda, colapso del empleo y metástasis generalizada " [La symptomatologie de la maladie: sténose aigüe des marchés financiers, arythmie sévère des équilibres globaux, thrombose dans les voies artérielles de l'argent due à la toxicité de la dette, obstruction de l'emploi et métastases généralisées],

"Socavón, cráter, metástasis de entropía terminal, fin de ciclo, de cielo y de era » [Orifice, cratère, métastase d'entropie terminale, fin de cycle, de ciel et d'ère],

«El tumor produjo una rápida metástasis en el conjunto del sistema y la desconfianza cundió en las relaciones entre entidades de crédito » [La tumeur a généré la prolifération rapide des métastases dans l'ensemble du système et la méfiance s'est installée dans les relations entre les entités de crédits],

«Esta metástasis financiera que tiene paralizados los mercados de liquidez "[Cette métastase financière qui paralyse les marchés de la liquidité],

«El estrangulamiento financiero de las PYMEs » [L'étranglement financier des PME],

«El estrangulamiento del crédito » [L'étranglement du crédit],

«El estrangulamiento es inminente » [L'étranglement est imminent],

«El nudo de estrangulamiento de liquidez de las empresas » [Le goulet d'étranglement de la liquidité des entreprises],

«En estos momentos de asfixia económica » [En cette période d'asphyxie économique], "Coger respiración y seguir aguantando » [Inspirer profondèment et tenir le plus longtemps possible],

"Desempleo masivo y asfixia a los ciudadanos " [Chômage massif et asphyxie des citoyens],

«La asfixia de las economías familiares » [L'asphyxie de l'économie des ménages],

«La subida de los impuestos va a simbolizar la sentencia de muerte para los bolsillos españoles » [L'augmentation des impôts symbolisera la sentence de mort pour le porte-monnaie des Espagnols],

"Sectores "heridos de muerte" como el de la construcción" [Des secteurs entiers "mortellement blessés" comme celui du BTP],

"El "crack" en la construcción fue una crónica de una muerte anunciada » [Le krach dans le bâtiment a été la chronique d'une mort annoncée],

«El sistema capitalista ha fallecido de muerte natural » Le système capitaliste est décédé de mort naturelle],

"La Moncloa se obceque en poner cataplasmas al paciente para bajarle una fiebre que no es la causa de la enfermedad sino el síntoma de una infección que sólo se puede abordar con un tratamiento quirúrgico de reformas estructurales " [La Moncloa pose aveuglèment des cataplasmes au patient pour faire baisser la fièvre qui n'est pas la cause de la maladie mais le symptôme d'une infection qui ne peut ête combattue que par un acte chirurgical de réformes structurelles],

"Para salir de la crisis a la que el socialismo sólo hace frente con cataplasmas y calmantes que no sólo no curan la enfermedad sino que la prolongan y agravan" [Pour sortir de la crise contre laquelle le socialisme ne lutte qu'avec des cataplasmes et des calmants qui ne font que prolonger et agraver la crise au lieu de la guérir],

«El Gobierno ha ocultado la realidad económica mientras ponía cataplasmas » [Le gouvernement a dissimulé la réalité économique en mettant des cataplasmes], "Una retórica voluntarista de cataplasmas o tiritas » [Une rhétorique volontariste de cataplasmes et de sparadrap].

\section{Champs lexicaux psychologiques}

75 Les observateurs ont remarqué que les crises boursières sont toujours des moments particuliers de la psychologie des marchés car les anticipations pessimistes voire catastrophistes accélérent dangereusement la spirale à la baisse ${ }^{65}$. En octobre 2008, Alain Minc n'a pas hésité à déclarer : «la crise est grotesquement psychologique ${ }^{66}$ ». Parmi les 
émotions dominantes véhiculées par le récit médiatique, l'analyse du corpus fait apparaître huit états psychologiques: l'incertitude, l'inquiétude, la peur et l'anxiété, l'espoir, la panique, le pessimisme, le désespoir et la colère dans une moindre mesure.

Les qualifications psychologiques de la crise se font sur un registre à la fois dramatique et anxiogène. Après l'abasourdissement face à la crise hypothécaire, la perplexité face aux faillites, l'incrédulité face à l'effondrement du marché, vient l'agitation et l'émoi à la lecture de la presse :

El desconcierto por la crisis hipotecaria, después la perplejidad ante las quiebras, el pasmo por la pérdida de fe, más tarde, la confusión ante el neocon transformado en neoconverso al intervencionismo estatal, el asombro por los planes de salvamento, la incredulidad ante el mercado puesto entre paréntesis. El estupor, por fortuna, ha dejado rastro. Ahora sabemos que la turbación con que hemos leído los periódicos estos meses no se debía a ignorancia o ingenuidad propias, sino a los ribetes de inverosimilitud que adquiría la realidad ${ }^{67}$.

La nette domination de l'incertitude (qui provoque l'inquiétude) et de la peur (qui se transforme très vite en panique) reflète une tonalité clairement négative. Ces émotions négatives n'épargnent ni les particuliers ni les acteurs économiques :

« Las hipotecas subprime son el centro de atención y la gran preocupación de los inversores »[Les hypothèques subprime sont le centre d'attention et la préoccupation majeure des investisseurs],

"Lo que incrementa la preocupación de que la crisis en el mercado de la vivienda se contagie al consumo y a otros sectores de la economía del país " [Ce qui augmente l'inquiètude quant au risque de contagion de la crise du marché immobilier au marché de la consommation et à d'autres secteurs économiques du pays],

«La principal fuente de preocupación de millones de españoles » [La principale source d'inquiètude de millions d'Espagnols],

"La máxima preocupación se centra en estos momentos en conocer la magnitud del ajuste » [Actuellement, la plus grande inquiètude concerne l'ampleur des mesures d'ajustement],

«El vicepresidente segundo del Gobierno y ministro de Economía, Pedro Solbes, mostró su preocupación por la existencia de incertidumbres que pueden afectar negativamente al crecimiento económico » [Le deuxième vice-président du gouvernement et ministre de l'Économie, Pedro Solbes, s'est déclaré inquiet face aux incertitudes qui peuvent affecter de façon négative la croissance économique],

«Un intento por calmar la preocupación social " [Une tentative pour calmer l'inquiètude sociale],

"¿Pánico en las bolsas? Algo de eso hay » [Panique dans les bourses ? Cela y ressemble], «El pánico se adueñó de los mercados financieros mundiales el jueves pasado » [La panique s'est emparée, jeudi dernier, des marchés financiers mondiaux],

"El pánico se apodera de las bolsas por temor a una crisis desbocada », [La panique s'est emparée des bourses par crainte d'une crise débridée],

«La crisis de las subprimes ha propiciado un extraño pánico al estallido de la burbuja inmobiliaria nacional » [La crise des subprimes a provoqué une étrange panique suite à l'éclatement de la bulle immobilière nationale],

«Pánico en la ciudadanía » [Panique des citoyens],

«Pánico a otra Gran Depresión » [Panique face à la menace d'une autre Grande Dépression],

«Hizo su aparición una situación de desconfianza en el sistema provocando un pánico en los mercados " [L'instauration d'un climat de méfiance vis-à-vis du système a provoqué la panique sur les marchés],

«Aquel jueves negro en el que cundió el pánico y se desplomaron todos los mercados » [Ce fameux jeudi noir qui a vu se propager la panique et l'effondrement de tous les marchés],

«Pánico hipotecario global » [Panique hypotécaire mondiale], 
« Las inyecciones de liquidez del BCE no han bastado para atajar el pánico » [L'injection de liquidités par la BCE n'a pas suffi à enrayer la panique],

"Los mercados viven una situación de "pánico" inmune a las medidas estatales " [Les marchés vivent des heures de "panique" sourde aux mesures du gouvernement].

\section{Champs lexicaux axiologiques} sur le système bancaire mondial étaient prévisibles, la crise financière a mis un certain temps à être prise en compte dans toute sa gravité non seulement par le gouvernement installé dans un véritable déni mais aussi par les médias qui ne s'y sont véritablement intéressés qu'à l'automne 2008. Si ces derniers se sont emparés tardivement du feuilleton de la crise, c'est parce qu'ils n'ont rien vu venir, se contentant de relayer la crise américaine sans analyse ni anticipation sur ses conséquences probables en Europe. Cependant, à partir de l'automne 2008, après la première onde de choc, ils l'ont exploitée tant et plus, en la présentant quotidiennement sous tous ses aspects dans les journaux télévisés, dans des programmes spéciaux réunissant journalistes et experts sur les plateaux de différentes chaînes, dans la Une et les éditoriaux des périodiques sans oublier les dossiers spéciaux que de très nombreuses revues ont consacrés à la crise.

83 L'analyse du corpus a permis de révéler que si dans un premier temps, lorsque la crise éclate aux États-Unis, les développements argumentatifs renvoient à la description de 
réalités factuelles (éclatement de la bulle, faillite de banques, etc.) et se fondent sur des relations de cause à conséquences explicites, dès lors que la crise atteint l'Espagne, on assiste à une dramatisation des analyses par le biais, essentiellement, de deux procédés discursifs : la métaphore et l'hyperbole.

\section{BIBLIOGRAPHIE}

CHARAUdeAu Patrick, « Le contrat de communication médiatique», Le français dans le monde, Numéro spécial, Médias : faits et effets, Paris, Hachette, 1994, p. 8-19.

Charaudeau Patrick, Le discours d'information médiatique. La construction du miroir social, Paris, Nathan / Institut national de l'audiovisuel, coll. « Médias-Recherches », 1997.

HUMBERT Jean-François, Rapport d'information $n^{\circ} 385$ (Sénat, session ordinaire 2010-2011), Commission des affaires européennes, 2011.

LAKOFF George et JoHnson Mark, Les métaphores dans la vie quotidienne, Paris, Les Éditions de Minuit (Propositions), 1985. Traduit de l'anglais par Michel de Fornel, en collaboration avec Jean-Jacques Lecercle.

LEBARON Frédéric, « La construction de l'opinion économique par les médias. Quelques remarques introductives ", dans Légitimation du discours économique, Colloque international, Centre d'études des mutations en Europe et l'Institut d'études européennes, Université de Paris 8 -Saint-Denis, 2001. Disponible sur <http://www.acrimed.org/article419.html>

LORDON Frédéric, La politique du capital, Paris, Odile Jacob, 2002.

MieCZNiKowski Johanna, Rocci Andrea et ZlatKova Gergana, «L'argumentation dans la presse économique et financière italienne ", Regards plurilingues sur les discours de la bourse et de la finance, Journée d'Études du Centre Interlangues Texte Image Langage (EA 4182), Université de Bourgogne, 26 février 2010.

RESCHE Catherine, «The Economist : discours de spécialité économique ou discours sur l'économie ?», dans S. Isani (dir.), Langues et cultures de spécialité à l'épreuve des médias, ILCEA [en ligne], $\mathrm{n}^{\circ}$ 11, 2009, mis en ligne le 30 avril 2009. Disponible sur <http://ilcea.revues.org/ index64.html>

VERCRUYSSE A., « Liquide, liquidité : termes et métaphores en langage économique », Travaux de Linguistique, 30, 1995, p. 65-81.

Wolton Dominique, Penser la communication, Paris, Flammarion, 1997.

\section{ANNEXES}




\section{Annexe 1. - Principaux termes (anglais-espagnol- français)}

\begin{tabular}{|c|c|c|}
\hline Anglais & Espagnol & Français \\
\hline BAD BANK & BANCO MALO & $\begin{array}{l}\text { STRUCTURE } \quad \text { DE } \\
\text { DÉFAISANCE }\end{array}$ \\
\hline BUBBLE & BURBUJA & BULLE \\
\hline $\begin{array}{l}\text { CREDIT DEFAULT } \\
\text { SWAP }\end{array}$ & $\begin{array}{l}\text { seguros de impago, permutas crediticias, opcion de } \\
\text { compra a futuro, permuta de moneda, permuta } \\
\text { financiera, crédito cruzado, crédito Swap fallido, } \\
\text { permutas cobertura por incumplimiento crediticio, } \\
\text { permuta de créditos impagados, swaps de } \\
\text { incumplimiento crediticio. }\end{array}$ & $\begin{array}{lr}\text { COUVERTURE } & \text { DE } \\
\text { DÉFAILLANCE } & \\
\text { DÉRIVÉS } & \text { SUR } \\
\text { ÉVÉNEMENTS } & \text { DE } \\
\text { CRÉDIT } & \\
\text { PERMUTATION } & \text { DE } \\
\text { L'IMPAYÉ } & \end{array}$ \\
\hline FORECLOSURE & EJECUCIÓN DE UNA HIPOTECA & SAISIE \\
\hline HEDGE FUNDS & FONDOS DE PROTECCION & $\begin{array}{ll}\text { FONDS } & \text { DE } \\
\text { COUVERTURE } & \end{array}$ \\
\hline MORTGAGE & HIPOTECA & HYPOTHÈQUE \\
\hline RECESION & RECESION & RÉCESSION \\
\hline REPOSSSESSION & RECUPERACIÓN & REPRISE \\
\hline SECURITIZATION & TITULIZACIÓN & TITRISATION \\
\hline SUBPRIME & $\begin{array}{l}\text { HIPOTECA DE ALTO RIESGO } \\
\text { CRÉDITO HIPOTECARIO DE ALTO RIESGO } \\
\text { HIPOTECA SUBPRIME HIPOTECA BASURA } \\
\text { HIPOTECA NINJA }\end{array}$ & $\begin{array}{l}\text { CRÉDIT } \\
\text { IMMOBILIER À } \\
\text { RISQUE } \\
\text { CRÉDIT } \\
\text { HYPOTHÉCAIRE À } \\
\text { RISQUE }\end{array}$ \\
\hline SWAP & $\begin{array}{l}\text { SEGUROS DE IMPAGO } \\
\text { PERMUTA FINANCIERA } \\
\text { PERMUTA CREDITICIA }\end{array}$ & SWAP \\
\hline SWAP CREDIT & $\begin{array}{l}\text { CRÉDITO SWAP } \\
\text { CRÉDITO CRUZADO }\end{array}$ & $\begin{array}{l}\text { CRÉDIT SWAP / } \\
\text { CRÉDIT CROISÉ }\end{array}$ \\
\hline
\end{tabular}




\begin{tabular}{|l|l|lr|}
\hline \multirow{2}{*}{ TARP PROGRAM } & PROGRAMA O PLAN DE ALIVIO DE ACTIVOS EN & PROGLEMAS (TARP) & $\begin{array}{l}\text { RACHAT } \\
\text { ACTIFS TOXIQUES }\end{array}$ \\
\hline TOXIC ASSETS & ACTIVOS TÓXICOS & ACTIFS TOXIQUES \\
\hline
\end{tabular}

\section{Annexe 2. - Petit glossaire des termes financiers}

\section{ASSET BACKED SECURITIES i.e ABS}

Terme non traduit.

Ce sont des titres dont l'émission est garantie par un ensemble d'actifs, généralement des créances privées. Le regroupement de celles-ci en un « pool » fractionné en parts les rend accessibles aux investisseurs. Ce sont des titres de créances émis sur des marchés de gré à gré fragmentés (over the counter, i.e OTC) sur lesquels les rares échanges sont nominatifs, bilatéraux et ne font pas l'objet d'une centralisation. Volumes et prix y sont par conséquent difficilement observables.

\section{COLLATERALIZED DEBT OBLIGATIONS i.e CDO}

Terme non traduit.

Ce sont des produits financiers structurés sous forme de tranches classées par ordre de séniorité (senior, mezzanine, junior) et adossés à des actifs. Pour certains d'entre eux, ce sont des produits de retitrisation d'ABS.

\section{CREDIT DEFAULT SWAPS i.e CDS}

Traduction en espagnol : seguros de impago, permutas crediticias, opción de compra a futuro, permuta de moneda, permuta financiera, Crédito cruzado, crédito Swap fallido, permutas de cobertura por incumplimiento crediticio, permuta de créditos impagados, swaps de incumplimiento crediticio.

Traduction en français : couvertures de défaillance, dérivés sur événement de crédit, permutation de l'impayé.

Créé en 1994 par Blythe Masters, un Credit Default Swap (CDS) est un contrat de protection financière par lequel un vendeur de protection s'engage, contre le paiement d'une prime, en cas d'événement affectant la solvabilité d'une entité de référence, à dédommager l'acheteur. L'acheteur de protection verse une prime ex ante annuelle calculée sur le montant notionnel de l'actif (souvent dit « de référence » ou « sousjacent »), au vendeur de protection qui promet de compenser ex post les pertes de l'actif de référence en cas « d'événement » de crédit précisé dans le contrat. C'est donc, sur le plan des flux financiers, comme un contrat d'assurance, une transaction non-financée, une exposition hors-bilan. Les CDS, travaillés hors bilan et hors bourse, permettaient de contourner toutes les règles prudentielles, et l'accès aux CDS n'était pas contrôlé par les pouvoirs publics. Par ailleurs, les CDS permettent de réduire les exigences en capitaux propres des banques puisqu'ils constituent une garantie contre le risque de défaut.

Largement vus comme une des grandes sources de la crise financière, la plus grave depuis 1929 , les CDS sont dans le collimateur de ceux qui veulent affermir les réglementations et resserrer le contrôle des activités bancaires. Les CDS sont considérés comme l'une des 
causes de la chute, le 15 septembre 2008, de l'American International Group (AIG), et l'une des sources de la diffusion incontrôlée des risques de crédit. Le marché des CDS est passé de 6,396 milliards de dollars américains en décembre 2004 à 57,894 milliards en décembre 2007, prenant le caractère d'une bulle financière.

\section{HEDGE FUNDS}

Traduction en espagnol : fondos de alto riesgo, fondos de cobertura, fondos de gestión alternativa y alto riesgo, fondos especulativos, fondos de inversión libre.

Traduction en français : fond de couverture.

Ce sont des fonds d'arbitrage spécialisés dans des investissements à haut risque dont la gestion relève d'un contrat proposé par le gestionnaire à l'investisseur avec très peu d'interférence réglementaire et qui poursuit un objectif de rentabilité élevé. Ces fonds d'investissement non cotés sont à vocation spéculative. La crise a commencé avec la fonte de deux d'entre eux, gérés par la banque Bear Stearns. Ces fonds très spéculatifs exploitent les anomalies du marché et les failles de la réglementation financière pour réaliser des opérations juteuses. Évoluant sous la forme de "partenariats privés", ils ne sont pas soumis aux mêmes obligations que d'autres types de fonds, et ne sont ainsi pas obligés de dévoiler la nature de leurs activités à des tiers.

\section{RECESSION}

Traduction en espagnol : recesión.

Traduction en français : récession.

Selon les conventions habituellement admises, un pays entre en récession lorsque son PIB diminue sur deux trimestres consécutifs.

\section{SECURITIZATION}

Traduction en espagnol : titulización.

Traduction en français : titrisation.

La titrisation est une technique qui consiste pour une banque à transférer aux marchés financiers (et donc à rendre liquides) des créances telles que des prêts immobiliers ou des crédits à la consommation et à l'investissement en transformant ces créances, par le passage à travers une société ad hoc, en titres financiers émis sur le marché des capitaux. La titrisation s'est imposée comme une technologie de défausse du risque. Elle permet aux établissements de crédit d'empocher des commissions en plaçant des crédits de plus en plus risqués auprès de débiteurs de moins en moins solvables sans s'exposer, a priori, aux pertes que vont générer les défaillances futures des emprunteurs.

La titrisation des crédits bancaires, développée aux États-Unis dès les années 1980, a été au cœur de toutes les polémiques. Elle s'est, en effet, trouvée en première ligne dans la contagion de la crise financière de 2007-2009 depuis le segment des crédits subprime jusqu'à l'ensemble du système monétaire et financier.

\section{SUBPRIME}

Traduction en espagnol : hipotecas de alto riesgo, hipotecas basura, hipotecas ninjas. Traduction en français : hypothèque à haut risque.

Type particulier de crédit immobilier hypothécaire qui s'est développé aux États-Unis durant la dernière décennie (il n'existait pas en Espagne ni en France). Proposé à des ménages financièrement fragiles, il est associé à un degré élevé de risque. Les défauts de 
paiement sur ce segment du marché du crédit ont provoqué des effets en chaîne, propageant la crise à l'ensemble du secteur bancaire et des marchés financiers.

\section{SWAP}

Traduction en espagnol : seguros de impago, permutas crediticias, opción de compra a futuro, permuta de moneda, permuta financiera, crédito cruzado, crédito SWAP fallido, permutas de cobertura por incumplimiento crediticio, permuta de créditos impagados, Swap de incumplimiento crediticio, intercambio de tipos, permuta de divisas, acuerdo de recompra, préstamo de divisas con pacto de recompra.

Traduction en français : emprunt généralisé du terme SWAP.

Le SWAP (de l'anglais to swap : échanger) ou l'échange financier (J.O. du 31 janvier 1990) est un produit dérivé financier. Il s'agit d'un contrat d'échange de flux financiers entre deux parties, qui sont généralement des banques ou des institutions financières. On parle de swap de change ou swap cambiste. Le mot swap désigne donc, dans le langage courant, un échange de flux financiers (calculés à partir d'un montant théorique de référence appelé notionnel) entre deux entités pendant une certaine période de temps. Contrairement aux échanges d'actifs financiers, les échanges de flux financiers sont des instruments de gré à gré sans incidence sur le bilan, qui permettent de modifier des conditions de taux ou de devises (ou des deux simultanément), d'actifs et de passifs actuels ou futurs.

Les swaps existent en fait depuis longtemps, quoique sous une forme informelle et non standardisée. Les premiers swaps sont apparus sur le marché des changes dans le courant du XIX ${ }^{e}$ siècle, entre les banques centrales, sous la forme de prêts croisés : chacune accordait à l'autre un prêt dans sa propre devise nationale, les deux prêts étant d'un montant équivalent et de même échéance.

\section{TARP Program}

Traduction en espagnol : Programa de Alivio de Activos en Problemas (TARP), Plan de Alivio de Activos en Problemas (TARP), Activos tóxicos, Plan de ayuda al sector financiero (TARP), Programa de alivio de activos problemáticos (TARP), Paquetes de rescate (TARP).

Traduction en français : Programme de rachat des actifs toxiques des banques.

Le Plan Paulson ou TARP (Troubled Asset Relief Program) est l'une des mesures mises en place par les États-Unis à partir de septembre 2008 pour faire face à la crise financière de 2008, elle-même enfantée par la crise des subprimes qui a débuté en 2007 et qui menaçait le système financier international. Il s'appuie sur l'Emergency Economic Stabilization Act of 2008, une loi initialement proposée par le Secrétaire au Trésor des États-Unis, Henry Paulson, et par le président de la Réserve fédérale des États-Unis Ben Bernanke. Initialement, ce plan prévoyait que le Département du Trésor des États-Unis achèterait des actifs toxiques américains, principalement des mortgage-backed securities, de banques faisant affaire aux États-Unis jusqu'à concurrence de 700 milliards USD. Le 11 novembre 2008, Henry Paulson, a radicalement modifié l'approche retenue : le Trésor américain prendra plutôt une prise de participation dans le capital des institutions financières les plus fragiles, augmentant ainsi leurs liquidités.

\section{TOXIC ASSETS}

Traduction en espagnol : activos tóxicos.

Traduction en français : actifs toxiques. 
L'expression « actifs toxiques » désigne des instruments de placements (actifs financiers) basés sur les subprimes devenus illiquides et entraînant une forte dépréciation des bilans, voire la faillite, des institutions financières qui les détiennent en portefeuille et qui appliquent la méthode comptable de la juste valeur. Le Département du Trésor des ÉtatsUnis a annoncé, le 18 septembre 2008, qu'il allait se porter acheteur de ces placements pour éviter une crise systémique, les modalités et les prix offerts n'étant toutefois pas précisés. Au début d'octobre 2008, le Sénat des États-Unis entérinent un plan qui permettra au Trésor des États-Unis d'acquérir ces actifs : le Plan Paulson.

FANNIE MAE (Federal National Mortgage Association) et FREDDY MAC (Federal Home Loan Mortgage Corporation) sont des organismes financiers qui assurent le refinancement de prêts immobiliers initiés par des banques américaines et qui transforment ensuite ces créances en obligations afin de les vendre sur les marchés boursiers. Entre l'été 2007 et l'été 2008 , ces sociétés ont perdu $90 \%$ de leur valeur en Bourse, ce qui a précipité leur faillite.

\section{NOTES}

1. Les simples dépêches d'agence de presse ont été exclues.

2. La presse espagnole, et les médias espagnols en général, sont très dynamiques. On recense 137 titres de presse et 12 millions de lecteurs environ. Concernant la presse écrite, l'Espagne connaît une situation différente de celle de la France. Du fait de l'organisation en Autonomies, la presse régionale possède un très fort poids économique et social et tient, de ce fait, une part essentielle dans le panorama de la presse quotidienne espagnole. C'est ainsi que, par exemple, la diffusion du quotidien catalan La Vanguardia dépasse largement les limites de la Catalogne.

3. Par exemple, la réduction de l'assiette des droits de succession, la réduction de l'assiette des droits de donation, la déductibilité des frais d'entretien, l'exemption de l'impôt foncier communal, l'exemption de l'impôt sur la fortune, etc.

4. Résidents relevant du régime communautaire : 2307770 essentiellement en provenance de la France, la Grande-Bretagne, l'Allemagne, le Portugal, la Roumanie et l'Italie. Résidents relevant du régime général : 2436399 (essentiellement Maroc, Équateur et Colombie) soit un total de 4744169 en 2010 (contre un total de 895720 résidents étrangers en 2000, de $2 \mathrm{M}$ en 2004 et de $3,5 \mathrm{M}$ en 2005). Entre 2000 et 2005, le nombre d'étrangers sur le territoire a donc été multiplié par 4 (source : INE, 29 avril 2010).

5. La location est très taxée et l'évolution des loyers contrôlée, ce qui décourage les bailleurs privés. Néanmoins, le marché noir locatif est très développé.

6. Ce qui explique les 1200000 de logements vides en janvier 2009.

7. Traditionnellement, les jeunes Espagnols figurent parmi les Européens qui mettent le plus de temps à s'émanciper : en 2010, 55 \% des 18-34 ans vit encore chez ses parents et près d'un quart des 30-34 ans. On les surnomme les « yeppies » (source : Consejo de la Juventud de España (CJE)).

8. En d'autres termes, dans un pays de 16,5 millions de familles, on compte entre 22 et 24 millions de maisons dont 3 à 4 millions de maisons vides. Sur l'ensemble des maisons construites durant la période 2001-2007, 28 \% sont vacantes à la fin de l'année 2008 (source : Institut Eurostat).

9. À titre d'exemples : $75 \%$ en Grèce, $74 \%$ en Belgique, $70 \%$ en Italie et au Luxembourg, $67 \%$ au Royaume-Uni, 55 \% en France, aux Pays-Bas et au Danemark, 43 \% en Suède.

10. Entre 1990 et 2007, le prix de l'immobilier a augmenté à un taux annuel cumulé de $8,4 \%$. Le montant de la dette financière accumulée par les ménages espagnols au second trimestre 2005 pour l'achat de biens immobiliers s'élève à $651168000000 €$, avec un rythme de croissance annuelle de $25 \%$ entre 2001 et 2005 (source : Institut Eurostat). 
11. L'émergence d'une telle bulle immobilière a été favorisée par le système bancaire espagnol et par la forte présence des Caisses d'épargne régionales qui maillent le territoire national. Les crédits immobiliers représentent $69 \%$ des prêts accordés par "les Cajas » (Caisses d'épargne) contre $52 \%$ pour les banques.

12. $97 \%$ des emprunts sont à taux variable malgré l'incitation des institutions financières et gouvernementales à prendre des prêts à taux fixe.

13. En juin 2010, les excès de la bulle immobilière sont estimés à 325 milliards d'euros et le taux global d'impayés du secteur immobilier à $9 \%$.

14. Le premier article recensé qui tire la sonnette d'alarme date du 7 février 2004 : "Société Générale ve un alto riesgo hipotecario en España ", Cinco Días.

15. Voir tableaux en annexe 1 et annexe 2 .

16. En janvier 2008, Leopoldo Abadía, consultant et ex professeur à l'IESE (Instituto de Estudios Superiores de la Empresa, Université de Navarre, actuellement la première école de commerce au monde dans la catégorie des programmes ouverts), publie sur son blog le premier article didactique d'une longue série pour expliquer le krach financier sous le titre de «La crisis ninja». Invité sur tous les plateaux de télévision et sur toutes les radios, il développera son étude dans l'ouvrage du même titre La crisis ninja y otros misterios de la economía actual (Espasa, Madrid, 2009), numéro 1 des ventes hors fiction. L'Espagne est le pays des ninjas : "Ahora los ninjas ya están entre nosotros, y no es que los hayamos importado, sino que son ninjas made in Spain » (dans « Los ninjas españoles: los mileuristas ", Gaceta de los Negocios, 15 août 2008).

17. Nous traduisons : « la dite, ce que l'on pourrait appeler, ce qui signifie, définie comme, etc. » 18. "Viaje al endeudado estilo de vida americano" (Voyage dans le style de vie américain endetté), Cinco Días, 26 février 2007. Nous avons relevé 22 occurrences entre février et juin 2007.

19. Prêt accordé aux personnes à haut risque crédit; hypothèque à haut risque accordée aux personnes peu solvables; crédits de mauvaise qualité et à haut risque.

20. Nous traduisons : "Secteur hypotécaire subprime, segment subprime, marché subprime. »

21. L'Eurogroupe est la réunion mensuelle (et informelle) des ministres des Finances des pays membres de la zone euro.

22. Nous traduisons: "Crédit facile, crédit vivre libre, crédit maintenant, crédit au, crédit utile, argent maintenant, crédit agile, argent expresse. »

Dans la réalité des faits, ces prêts personnels sont des prêts subprime, accordés sans considération de la solvabilité des emprunteurs, à des taux d'intérêt élevés quasi usuriers pour la consommation. Ces prêts sont accordés par des entités indépendantes spécialisées en crédits subprime (EFC, établissements financiers de crédit) comme Mediatis ou Cofidis ou des filiales de banques (Santander Consumer, Dinero Express de BBVA) non autorisées par la loi à accepter des dépôts.

23. «La llamada crisis de las hipotecas subprime no existe en España, ya que el mercado hipotecario español tiene una excelente cobertura legal y, en general, la calidad de las hipotecas españolas está fuera de duda y en ningún caso debe compararse con la crisis norteamericana » [Ce que l'on appelle la crise des subprimes n'existe pas en Espagne; le marché des hypothèques espagnol bénéficie d'une excellente couverture juridique et, dans l'ensemble, la qualité des hypothèques espagnoles ne peut être mise en cause; il ne peut $\mathrm{y}$ avoir, en aucun cas, comparaison avec la crise aux États-Unis].

24. "Uno de cada diez hogares tiene una deuda que triplica su renta anual ", Cinco Días, 14 décembre 2007 [Une famille sur dix a une dette trois fois supérieure à son revenu annuel].

25. «España en crisis. Las consecuencias», El Mundo, 24 juin 2008 [L'Espagne en crise. Les conséquences].

26. Déclarations faites sur la station de radio Onda Cero, le 5 mai 2008, et reprises par une grande partie de la presse écrite et audio-visuelle, 
27. «Los expertos confirman que hay crisis » [Les experts confirment qu'il y a une crise], Gaceta de los Negocios, 25 juillet 2008 ; «Las verdades que no quiere escuchar Zapatero » [Les vérités que Zapatero ne veut pas entendre], Gaceta de los Negocios, 25 juillet 2008 ; « Baño de realidad » [Bain de réalité], El País, 25 juillet 2008; «Negacionismo económico 'versus' credibilidad» [Négationisme économique versus crédibilité], El País, 25 juillet 2008 ; «El Gobierno se da de bruces con la crisis» [Le gouvernement tombe de tout son long sur la crise], El País, 25 juillet 2008.

28. Favorable à la mise en place rapide d'une politique de rigueur, l'ancien commissaire européen, Pedro Solbes, ministre de l'Économie et des Finances depuis 2004, préfère quitter le gouvernement en avril 2009.

29. «Un tercio del volumen total del crédito hipotecario en España ya está titulizado », Cinco Días, 9 février 2007 [En Espagne, un tiers du volume total du crédit hypotécaire est d'ores et déjà titritisé].

30. La Vanguardia (5 octobre 2008): "No hay que preocuparse, nos dicen, pues el sistema de titulización español es muy diferente al de EE.UU. Las instituciones españolas usan el principio de originate to hold (generan títulos y mantienen la gran mayoría) en lugar de originate to distribuye (generar títulos y venderlos) » [Il n'y a aucune inquiètude à avoir, nous dit-on, car le système de titrisation espagnol est très différent de celui des États-Unis. Les institutions espagnoles fonctionnent sur le principe du originate to hold (créer des titres pour les garder) et non sur celui du originate to distribuye (créer des titres pour les vendre)].

31. Pour financer la forte hausse des hypothèques, les entreprises ont à nouveau eu recours à la titrisation des crédits (transformés en dette pour capter les ressources); lors de la clôture du précédent exercice, les titrisations ont atteint 99 milliards 928 millions d'euros (soit 39,9\% de plus qu'en décembre 2005) ainsi répartis : 47 milliards 184 millions pour les caisses d'épargne (+ $43,5 \%)$; 35 milliards 905 millions pour les banques $(+35,1 \%) ; 9$ milliards 842 millions pour les coopératives de crédit $(+40,1 \%)$ et 6 milliards 998 millions pour les établissements de crédit.

32. "La crisis acaba con la titulización como producto de mercado », Cinco Días, 4 mars 2010 [La crise a mis fin aux titrisations en tant que produits du marché financier].

33. Nous traduisons: «La création d'un bad bank auquel les banques peuvent vendre leurs mauvaises créances. »

34. "Solbes descarta aplicar en España la idea de un "banco malo" para los activos problemáticos del sector financiero ", EFE, 9 février 2009 [Solbes rejette l'idée de créer, en Espagne, un "banco malo" pour les actifs douteux du secteur financier].

35. Expansión, 18 mars 2009 : «La création d'un banco bueno (une bonne banque) qui recueillerait les actifs d'une entité en difficulté et qui serait une contre-proposition au banco malo (mauvaise banque) dont on parle en Europe."

36. ABC, 27 janvier 2009 ; Dow Jones en español, 2 février 2009 ; Gaceta de los Negocios, 3 février 2009. 37. «En Allemagne, on a récemment eu recours à un modèle plus simple, celui de banque défectueuse, pour gérer les actifs défectueux des Landesbanken.»

38. Durant le premier trimestre 2008, on enregistre 156 déclarations de faillite dans le secteur immobilier (soit $40 \%$ du total des faillites, avec une augmentation de $75 \%$ par rapport au premier trimestre 2007).

39. Extrait de: «Berlín destina 40.000 millones más a luchar contra la crisis ", Expansión, 20 décembre 2008. [Berlin consacre 40 milliards de plus pour lutter contre la crise].

40. Extrait de : «El fantasma del déficit acecha a las potencias », El Economista, 11 décembre 2008 [Le fantôme du déficit guette les puissances].

41. "Creciente deterioro fiscal limita los planes destinados a inyectar estímulo a la economía ", Diario Financiero, 14 décembre 2009 [La détérioration fiscale croissante limite les plans de relance économique]. 
42. Article 128 de la Constitution espagnole :

1. Toute la richesse du pays dans ses différentes formes et quel que soit celui à qui elle appartient est subordonnée à l'intérêt général.

2. L'initiative publique est reconnue dans l'activité économique. Une loi pourra réserver au secteur public des ressources ou des services essentiels, tout particulièrement en cas de monopole, et décider également le contrôle d'entreprises lorsque l'intérêt général l'exigera.

43. La Gaceta, 14 décembre 2007 : «El efecto del plan de rescate coordinado el miércoles por los bancos centrales para frenar la crisis crediticia y agilizar la liquidez ha sido efímero. Tras lograr insuflar un hilo de optimismo, las dudas de su efectividad reaparecieron ayer con fuerza. »

44. La première occurrence apparaît dans Expansión, le 10 mars 2007 : «Otra fórmula son las coberturas tipo swap (intercambio de tipos) » [Les couvertures type swap (rachat de créances) sont une autre formule].

45. Nous traduisons : " en créant un hedge fund pour la mise en œuvre de cette stratégie. "

46. "Los "hedge fund" avanzan ", La Vanguardia, 14 décembre 2003 [Les fonds d'investissement appelés hedge fund ou fonds d'investissement alternatifs ou encore à haut risque]. En 2003, on relève 7 occurrences du terme hedge fund.

47. "El éxito de los fondos extranjeros ", Expansión, 17 avril 2006 [Le succès des fonds étrangers]. 48. "BBVA comercializa el primer "hedge fund" en España", Cinco Días, 13 novembre 2006. [BBVA commercialise le premier 'hedge fund' en Espagne]. L'agence leader sur le marché espagnol est Fitch rating, Banco Bilbao Vizcaya Argentaria.

49. «El talón de Aquiles del nuevo capitalismo », El País, 1 mai 2007 [Le talon d'Achille du nouveau capitalisme]. Nous traduisons la citation : «les outils du nouveau capitalisme américain, les hedge funds et le private equity, dans le cadre des politiques de dépècement des entreprises et de réduction d'emplois, ont pour objectif principal la recherche d'une forte rentabilité $(25 \%$ environ) à court terme. »

50. «Dice ¿por error? la palabra "crisis" y ve la recuperación desde julio de 2009 », El Mundo, 9 mai 2008 : «Pasaban ya las 14.00 horas cuando se pudo oír de los labios del Vicepresidente económico la palabra prohibida. La que ha negado tanto él como el presidente del Gobierno, José Luis Rodríguez Zapatero. Es decir, el tenebroso término de "crisis" para definir la actual situación económica » [Il prononce (un lapsus ?) le mot "crise" et prévoit la reprise pour juillet 2009. [...] Peu après 14 heures, on a entendu de la bouche même du vice-président le mot interdit, le mot nié tant par lui que par le président du gouvernement, José Luis Rodríguez Zapatero, pour définir la situation économique actuelle : l'obscur terme de "crise"].

51. "Zapatero prevé un crecimiento débil, pero no un "estancamiento" duradero ", Cinco Días, 24 juin 2008.

52. Nous traduisons : «L'Espagne va bien, [...] Papa État a une tirelire bien pleine grâce à de nombreuses années d'excédent. »

53. Nous traduisons : «Le président du gouvernement, José Luis Rodríguez Zapatero, a affirmé aujourd'hui, en évoquant la détérioration des indicateurs macro-économiques durant les derniers mois, "qu'on ne peut pas ignorer qu'il se passe des choses" au sein de l'économie espagnole mais il a insisté sur le fait "qu'on ne doit pas exagérer". »

54. "Société Générale ve un alto riesgo hipotecario en España ", Cinco Días, 7 février 2004. Nous traduisons : « Il y a une bulle immobilière, déclare la banque française. Les entités financières espagnoles prennent un risque beaucoup plus grand que dans le reste de l'Europe en accordant des prêts hypothécaires. Véronique Riches-Flores, chef économiste Europe à la Société Générale, tire la sonnette d'alarme quant à la bulle immobilière. »

55. Voir note 23, p. 12.

56. Cette dispositio est construite sur le modèle du schéma générique des rapports issus des banques centrales et autres institutions financières : le "compte rendu " présente un état des lieux rigoureux, fiable et reproductible du domaine économique ou financier analysé ; il est 
subordonné « aux prévisions » présentées par l'institution sur la base de simulations fondées sur des modèles économiques qui seront décisives dans l'acte d'évaluation (Miecznikowski, Rocci et Zlatkova, 2010).

57. Les articles de presse abondent, nous n'en citerons que quelques-uns : « Doctor, mi piso no se vende» [Docteur, mon appartement ne se vend pas], El Mundo, 18 janvier 2008 ; «Tocomocho» [Duperie], La Voz de Galicia, 27 avril 2008 ; « Un año de mentiras » [Un an de mensonge], Gaceta de los Negocios, 9 août 2008 ; «La mentira y sus estragos » [Le mensonge et ses affres], Gaceta de los Negocios, 25 avril 2009 ; «Los verdugos y las víctimas de la crisis » [Les bourreaux et les victimes de la crise], Cinco Días, 3 février 2009 ; «Dos años de "thriller" con final abierto » [Deux ans de "thriller", la fin reste à écrire], El País, 9 août 2009.

58. Donc, parce que, en effet, en raison de, en dépit de, mais, toutefois, néanmoins, bien que, alors que, malgré, etc. - Ainsi, donc, or, etc. - En raison de, en effet, c'est-à-dire, soit, etc.

59. Le chiffre cité inclut les occurrences des variantes suivantes : crisis bursátil (58 occurrences), crisis de las bolsas (2 060 occurrences), crisis del mercado bursátil (94 occurrences), desplome bursátil (35 occurrences), debacle bursátil (7 occurrences) et situación bursátil crítica (7 occurrences).

60. Bourrasque, tempête, cyclone, ouragan, etc.

61. Débâcle, désastre, catastrophe, tsunami, tremblement de terre, etc.

62. Indigestion, contagion, hémorragie, métastases, cancer, gangrène, folie, étouffement, asphyxie, pandémie, paralysie, etc.

63. Dans l'article publié dans $A B C$, le 22 février 2009 sous le titre de «Humor en tiempos de crisis ", le journaliste résume en une phrase les termes récurrents du discours de presse depuis 2007 : « la economía se hunde, los bancos se tambalean y se avecina la debacle de casi todo, en la forma de un apocalíptico "tsunami" de "ninjas" hipotecados " [L'économie se noie, les banques tanguent, la débâcle approche sous forme d'un apocalyptique tsunami de ninjas hypothéqués].

64. "Gripe americana ", El País, 22 janvier 2008. Dans le champ médical, nous avons relevé 1568 occurrences.

65. L'inverse est tout aussi vrai: les anticipations optimistes voire euphoriques dopent le mouvement à la hausse.

66. Invité de Parlons Net (France Info, samedi 11 octobre 2008), Alain Minc, ancien président du Conseil de surveillance du Monde et conseiller des grands patrons et de Nicolas Sarkozy, a déclaré : « La crise est grotesquement psychologique. »

67. «Se acabó el estupor», $A B C, 4$ décembre 2008. Nous traduisons: "Le désordre créé par la crise des hypothèques puis la perplexité provoquée par les faillites, la stupéfaction générée par la perte de foi, et plus tard la confusion suscitée par les néocon- transformés en néo-convertis à l'État interventionniste, l'ahurissement face aux plans de sauvetage, l'incrédulité par rapport au marché mis entre parenthèses. La stupeur, fort heureusement, a laissé des traces. Nous savons aujourd'hui que le trouble provoqué, ces derniers mois, par la lecture des périodiques n'était pas dû à notre ignorance ou à notre naïveté mais bien plutôt à toutes les invraisemblances qui truffaient la réalité. »

\section{RÉSUMÉS}

Nous nous proposons d'analyser dans cet article la manière dont la presse écrite espagnole a présenté la crise financière de 2008. Cette crise ayant touchée l'Espagne de manière très 
spécifique, il nous a semblé utile de brosser, dans un premier temps, le cadre macroéconomique de l'éclatement de la bulle immobilière. L'étude quantitative (lexicométrie) et qualitative (sémantique) est basée sur un corpus constitué à partir des sites Internet des quotidiens espagnols (presse spécialisée et presse généraliste, nationale et régionale), au moyen du moteur de recherche FACTIVA. Après avoir défini une liste de termes spécifiques à la crise financière, nous avons tout d'abord établi une chronologie de l'arrivée des mots de la crise en Espagne en dégageant des pics d'usage de ces termes et de leur traduction, avant de nous pencher sur les prolongements métaphoriques et phraséologiques propres à la crise financière.

El estudio que presentamos enfoca el análisis, en el discurso periodístico, de los términos especializados de corte financiero propios a la crisis financiera de 2008. Dada la especificidad del caso de España, presentaremos primero los datos macroeconómicos que caracterizan la burbuja inmobiliaria española, para acometer luego el estudio cuantitativo (estadísticas lexicales) y cualitativo (semántico) de los términos del corpus financiero, seleccionado en la prensa digital, nacional y regional, de corte especializado y divulgativo, mediante el motor de búsqueda FACTIVA. Los términos de la crisis, y su traducción cuando la hay, han sido seleccionados, analizados y cuantificados por orden cronológico de irrupción en el discurso periodístico, a lo largo de la crisis. La última parte de nuestro estudio abarca los aspectos metafóricos y fraseológicos del discurso periodístico.

\section{INDEX}

Palabras claves : crisis financiera, discurso especializado, discurso periodístico, metáforas, términos de la crisis, traducción

Mots-clés : crise financière, discours de presse spécialisée, discours journalistique, métaphores, mots de la crise, traduction 